\title{
Asymmetric Synthesis of the Aminocyclitol Pactamycin, a Universal Translocation Inhibitor
}

\author{
Robert J. Sharpe, Justin T. Malinowski, and Jeffrey S. Johnson* \\ Department of Chemistry, University of North Carolina at Chapel Hill, Chapel Hill, North Carolina \\ 27599-3290
}

\begin{abstract}
An asymmetric total synthesis of the aminocyclopentitol pactamycin is described, which delivers the title compound in 15 steps from 2,4-pentanedione. Critical to this approach was the exploitation of a complex symmetry-breaking reduction strategy to assemble the $\mathrm{C} 1, \mathrm{C} 2$, and $\mathrm{C} 7$ relative stereochemistry within the first four steps of the synthesis. Multiple iterations of this reduction strategy are described, and a thorough analysis of stereochemical outcomes is detailed. In the final case, an asymmetric Mannich reaction was developed to install a protected amine directly at the $\mathrm{C} 2$ position. Symmetry-breaking reduction of this material gave way to a remarkable series of stereochemical outcomes leading to the title compound without recourse to non-strategic downstream manipulations. This synthesis is immediately accommodating to the facile preparation of structural analogs.
\end{abstract}

\section{INTRODUCTION}

Nature continues to test the state of the art in organic synthesis by providing chemists with both structurally complex and biologically relevant molecules. Construction of these natural products often requires the expansion of known synthetic methods to previously unreported substrate classes or the development of new approaches for the assembly of natural frameworks. ${ }^{1}$ Isolated in 1961 from Streptomyces pactum var. pactum, pactamycin (1) remains one of the most complex aminocyclopentitol antibiotics known, bearing a remarkable array of unique functionality and exceptional bioactivity. ${ }^{2}$

Pactamycin exhibits activity against both Gram-positive and Gram-negative bacteria and is a powerful antitumor, antiviral, and antiprotozoal agent. By acting as universal inhibitor of translocation, pactamycin is known to inhibit protein synthesis via a specific binding event within the $30 \mathrm{~S}$ ribosomal subunit. ${ }^{4}$ Cytotoxicity levels as high as $\mathrm{IC}_{50}=53 \mathrm{nM}$ against certain human cell lines have hindered its medicinal development; ${ }^{5}$ however, a number of biosynthetically-engineered congeners have been prepared which display diminished toxicity. These data have reignited promise for the investigation of structure-activity relationships (SAR) of 1 towards the goal of obtaining a useful drug molecule. ${ }^{7}$ Thus, the necessity of a practical and flexible synthesis of $\mathbf{1}$ is paramount for the success of such endeavors.

Pactamycin bears a densely-functionalized cyclopentane core featuring six contiguous stereogenic centers, three of which are fully-substituted. ${ }^{8}$ Unusual dimethylurea, aniline, and

Corresponding Author, jsj@unc.edu.

ASSOCIATED CONTENT

Supporting Information. Additional experimental procedures, characterization and spectral data for all compounds, and crystallographic data (CIF). This material is available free of charge via the Internet at http://pubs.acs.org. 
salicylate functional groups adorn the core structure, presenting numerous synthetic challenges. These issues have been addressed in a number of approaches as synthetic interest in pactamcyin has flourished over the past decade. Hanessian and coworkers reported the landmark total synthesis in $2011,9,10$ and Isobe, Knapp, Looper, Nishikawa, and our group have disclosed access to advanced core intermediates by varying methods. ${ }^{11-15}$ An inspection of these approaches reveals two common challenges one faces in assembling the core structure: i) execution of chemo- and stereoselective reactions in a highly congested chemical environment and ii) the method by which the unusual functionality of $\mathbf{1}$ is introduced. The Hanessian group observed of numerous side reactions due to functional group propinquity. ${ }^{9,10}$ Looper and Haussener also noted the importance of the order in which functional group manipulations were executed. ${ }^{13}$ Approaches to introducing the unique $\mathrm{C} 1$ dimethylurea have heretofore relied largely upon the use of oxazoline or oxazolidinone protecting groups, necessitating downstream deprotection and chemoselective acylation. In the development of a synthesis plan, we took note of these issues and sought to develop a synthesis of $\mathbf{1}$ that rapidly assembled the core structure and incorporated all unique functionality in the absence of non-strategic redox and protecting group manipulations. ${ }^{16}$

In 2012, we presented an initial report on our efforts toward a synthesis of $\mathbf{1},{ }^{15}$ and earlier this year this work culminated in a 15-step asymmetric total synthesis. ${ }^{17}$ Herein, we present a full account of our studies on pactamycin encompassing a modification of our original route to accommodate early-stage incorporation of the $\mathrm{C} 2$ amine functionality. A symmetrybreaking reduction for rapid access to the $\mathrm{C} 1 / \mathrm{C} 2 / \mathrm{C} 7$ stereotriad was developed, and an emphasis was placed on incorporating pactamycin's unique functionality in its final form to obviate downstream functional group adjustment or protecting group manipulation. This flexible route, we surmised, would provide access to $\mathbf{1}$ in a manner amenable to the synthesis of analogs for biological examination.

Our original retrosynthetic disconnection began with simplification of $\mathbf{1}$ to functionalized cyclopentane 2 (Scheme 1). C2 (allylic) functionalization, C4 hydroxylation, and C3 aniline installation might be possible from a $\mathrm{C} 3-\mathrm{C} 4$ alkene in cyclopentene $\mathbf{3}$, a compound that was expected to be accessed by ring-closing metathesis (RCM). The requisite precursor would be derived from nucleophilic addition to methyl ketone 4 . We surmised that this addition could occur either by inter- or intramolecular nucleophile delivery, the latter facilitated by attachment to the $\mathrm{C} 7$ secondary alcohol. Two approaches to $\beta$-hydroxyketone $\mathbf{4}$ were envisioned, dependent upon the identity of the R-substituent. For R = OMe (5), we proposed an enantioselective Tsuji-Trost allylation of ketoester $\mathbf{7}$ followed by diastereoselective ketone reduction and ester $\rightarrow$ ketone conversion. ${ }^{15,18}$ Alternatively, if $\mathrm{R}=\mathrm{Me}(\mathbf{6})$, we would invoke an enantioselective, symmetry-breaking diketone monoreduction, exploiting the hidden symmetry (see outlined region in Scheme 1) we perceived in the northeast quadrant of $\mathbf{1} .{ }^{19}$ Critical to our strategy in either case was the early-stage installation of the dimethylurea functionality in its final, native form, an approach divergent from those previously reported. a-Ureidodicarbonyls $\mathbf{7}$ or $\mathbf{8}$ would serve as our points of origin, synthesized from commodity chemicals (methyl acetoacetate $\mathbf{9}$ or 2,4-pentanedione 10, respectively).

A summary of our initial efforts is outlined in Scheme 2. ${ }^{15}$ Ester 11, prepared via the strategy outlined in Scheme 1, was treated with $\mathrm{Me}_{3} \mathrm{SiCH}_{2} \mathrm{Li}$ to afford $\beta$-silyloxyketone 12 poised for nucleophilic addition. From 12, a screen of nucleophiles and conditions were investigated for access to the requisite $\mathrm{C} 5$ alcohol; however, while addition of a model 2propenylmetal nucleophile mediated by $\mathrm{CeCl}_{3}$ proceeded in good yield, this reaction gave consistent preference for the undesired epimeric C5 configuration (13). This stereochemical outcome necessitated the synthesis of ketone 14, which upon methide addition mediated by 
$\mathrm{CeCl}_{3}$, provided the desired $\mathrm{C} 5$ stereochemistry with $>20: 1$ diastereoselection. This intermediate was then elaborated to $\mathbf{1 5}$ in three steps. Experiments directed toward installation of the $\mathrm{C} 2$ primary amine from $\mathbf{1 5}$ or its derivatives were extensively investigated in parallel with some of the studies described below, but ultimately failed to introduce the desired functionality.

\section{RESULTS AND DISCUSSION}

\section{Desymmetrization Approach}

While the above route was scalable and effective for accessing advanced intermediate 15, the synthesis of ketone $\mathbf{1 4}$ required a number of non-strategic redox and protecting group manipulations and lacked efficiency. As a result, we sought a streamlined approach to its synthesis. Cognizant of the undesired stereoselectivity encountered in intermolecular addition to methyl ketone 12, we envisaged that an intramolecular addition might provide the opposite facial preference. Delivery of a tethered nucleophile from the C7 hydroxyl followed by reduction and ring-closing metathesis would intercept our previous intermediate 15. This intermediate could be synthesized from our proposed enantioselective desymmetrization strategy from urea $\mathbf{6}$, the diketone analog of $\mathbf{5}$.

The diketone reduction precursor 6 was prepared in three steps (Scheme 3). The reaction of 2,4-pentanedione 10 with para-acetamidobenzenesulfonyl azide $(p \mathrm{ABSA})^{20}$ and $\mathrm{Et}_{3} \mathrm{~N}$ afforded the corresponding diazoketone in nearly quantitative yield. An $\mathrm{N}-\mathrm{H}$ insertion reaction analogous to that used in our previous studies delivered a-ureidodiketone $\mathbf{8}$ in $67 \%$ yield, ${ }^{21}$ and Tsuji-Trost allylation provided the necessary diketone precursor 6 in $81 \%$ yield. Working first to optimize the racemic reaction, we began screening reducing agents and conditions for selectivity. Gratifyingly, $\mathrm{LiAl}\left(\mathrm{O}^{t} \mathrm{Bu}\right)_{3} \mathrm{H}$ (LTBA) emerged early in our evaluation, providing $\beta$-hydroxyketone $( \pm)-\mathbf{1 7}$ in $75 \%$ yield with $>20: 1$ diastereoselection. The desired stereochemistry was confirmed via the TBS protection of keto alcohol $\mathbf{1 7}$ and direct comparison with $\mathbf{1 2}$, which had been independently synthesized via our previous route. ${ }^{15}$ We speculate that this reduction proceeds via chelated structure $\mathbf{1 6}$ in which steric demand of the dimethylurea functionality directs hydride addition to the least hindered face of the enantiotopic ketones, delivering ( $\mathbf{\pm}) \mathbf{- 1 7}$ in high selectivity.

From $\beta$-hydroxyketone 17, we began investigating intramolecular additions to the $\mathrm{C5}$ ketone. We were encouraged by the work of Crimmins and coworkers in the use of organocuprate nucleophiles for initiating intramolecular, alkylative cyclizations and surmised that an appropriately selected pronucleophile on the $\mathrm{C} 7$ hydroxyl could provide the desired reactivity. ${ }^{22}$ Thus, acylation of monoalcohol 17 with 2-butynoic acid delivered ynoate $\mathbf{1 8}$ in $79 \%$ yield. This esterification set the stage for the proposed cyclization. $\mathrm{Me}_{2} \mathrm{CuLi}$ emerged from a screen of known conjugate nucleophiles and conditions to deliver lactone 19 in 53\% yield and 3:1 dr. The desired relative configuration of the $\mathrm{C} 1 / \mathrm{C} 5 / \mathrm{C} 7$ stereotriad was confirmed by nOesy analysis.

At this juncture, only reduction remained to provide triol 20; this intermediate would effectively intercept the synthesis of cyclopentanone $\mathbf{1 5}$ in a highly efficient manner. However, an exhaustive screen of reducing agents and conditions failed to provide alcohol 20. Hindered reducing agents such as DIBAL-H and LTBA displayed no reactivity even at elevated temperatures, while unhindered reducing agents $\left(\mathrm{LiAlH}_{4}\right.$, Super-Hydride $\left.{ }^{\circledR}\right)$ resulted only in complex mixtures or reduction of the dimethylurea functionality. Additionally, attempts at ring opening of $\mathbf{1 9}$ via transesterification to its corresponding ester or thioester failed to show any desired reactivity. 
Having reached a second impasse, we began to form conclusions regarding our original and revised strategies. First, early-stage incorporation of the dimethylurea functionality, while a strategic risk at the onset of this work, had proven useful in directing desirable stereochemical outcomes in each of our initial routes. The impressive diastereoselectivity accessed from symmetry-breaking reduction of diketone $\mathbf{6}$ gave us cause to incorporate this strategy again in future routes to $\mathbf{1}$; however, neither our previously reported approach nor the above strategy addressed a major problem facing the endgame of our synthesis, namely, the late-stage installation of the primary amine at $\mathrm{C} 2$. In devising a new approach, we envisioned enantioselective installation of $\mathrm{C} 2$ functionality on ureidodiketone $\mathbf{8}$ prior to the symmetry-breaking reduction (Scheme 4). Monoreduction of this substrate would provide access to the $\mathrm{C} 1 / \mathrm{C} 2 / \mathrm{C} 7$ stereotriad within the first 4 steps of the synthesis, from which strategic manipulation of the available functional handles might give expedient access to $\mathbf{1}$. Beginning from the previously synthesized a-ureidodiketone $\mathbf{8}$, an enantioselective TsujiTrost allylation with difurylidene acetate $\mathbf{2 1}$ would install a 2-furyl group at the $\mathrm{C} 2$ center (22); we felt that this group could function as an amine surrogate via downstream oxidative cleavage and Curtius rearrangement. ${ }^{24}$ Since the ideal functionality at $\mathrm{C} 2$ would be the amine itself, a catalytic, asymmetric Mannich reaction of $\mathbf{8}$ with a strategically configured imine such as $\mathbf{2 3}$ was projected to deliver diketone $\mathbf{2 4}$ with carbamateprotected amine installed directly at $\mathrm{C} 2 .{ }^{25}$

In both the allylation and Mannich scenarios, enantioselective formation of the $\mathrm{C} 2$ asymmetric center would establish the lone stereochemical element that would be responsible for all subsequent diastereoselective manipulations. The ensuing diastereoselective symmetry-breaking monoreduction of a chiral diketone would be the key for controlling the $\mathrm{C} 1 / \mathrm{C} 7$ configurations and would require effective guidance from the initially-installed $\mathrm{C} 2$ stereocenter. The identities of the alkene termini in the generic structures $\mathbf{2 1}$ and $\mathbf{2 3}$ can be disregarded since downstream operations would purge these functionalities. Both of these proposed pathways would deliver the entire core skeleton of $\mathbf{1}$ within the first 3 steps. Equipped with these new hypotheses, we began pursuing each in parallel.

\section{C2-Furan Approach}

Our first challenge in realizing the Tsuji-Trost allylation approach was the synthesis of the allylic acetate 21, which surprisingly appears to be a new compound (Scheme 5). To this end, reduction of difurylpropenone $\mathbf{2 5}$ afforded the corresponding alcohol 26; however, upon concentration of the crude mixture this product rapidly decomposed. The observed decomposition was unexpected since this compound had been previously reported no note had been made regarding its instability. ${ }^{26} \mathrm{~A}$ screen of conditions designed to circumvent this problem revealed that $\mathrm{NaBH}_{4}$ reduction of $\mathbf{2 5}$ followed by immediate acylation using $\mathrm{Et}_{2} \mathrm{O}$ as the solvent provided $\mathbf{2 1}$ in crude form. ${ }^{27}$ Acetate $\mathbf{2 1}$ was also found to be unstable, but could be stored in solution for up to $30 \mathrm{~d}$ at $0{ }^{\circ} \mathrm{C}$.

With acetate $\mathbf{2 1}$ in our possession, the reaction of diketone $\mathbf{8}$ with difurylidene acetate $\mathbf{2 1}$ under the previously optimized allylation conditions afforded C2-functionalized diketone $( \pm)$ $\mathbf{- 2 7}$ in $80 \%$ yield. From this compound, we began to examine conditions by which we might effect symmetry-breaking reduction. Monoreduction of the chiral diketone 27 presents a more complicated problem than the reduction of diketone $\mathbf{6}$, since four diastereomeric products can result from the former. Exposure of diketone $\mathbf{2 7}$ to our previously optimized desymmetrization conditions (LTBA, THF, $-40{ }^{\circ} \mathrm{C}$ ) resulted only in retro-aldol decomposition. A screen of reducing agents revealed that the reaction of 27 with $\mathrm{LiAl}\left(\mathrm{O}^{t} \mathrm{Bu}\right)$ $\left({ }^{i} \mathrm{Bu}\right)_{2} \mathrm{H}(\mathrm{LDBBA})^{28}$ afforded mono-alcohol 28 with moderate diastereoselectivity (4:1 28: $\Sigma$ other diastereomers). While the reduction of diketone $\mathbf{6}$ (lacking any $\mathrm{C} 2$ substituent) 
required warmer temperatures and extended reaction times, reduction of $\mathbf{2 7}$ was complete within 10 min at $-78{ }^{\circ} \mathrm{C}$. An X-ray diffraction study of the major diastereomer confirmed the exact relative configuration needed for elaboration to 1 . While we envision a chelation mode similar to transition structure $\mathbf{1 6}$ might be taking place in this reduction, the involvement of the $\mathrm{C} 2$ furan in directing the $\mathrm{C} 1 / \mathrm{C} 7$ relative configuration and its dramatic effect on the reactivity are not well understood.

Having accessed this key intermediate, we proceeded to test conditions for functionalization of the C5 methyl ketone. Based on our previous work, ${ }^{15}$ we anticipated potential stereoselectivity and reactivity problems associated with nucleophilic addition to the C5 carbonyl and accordingly decided to invoke the ability of $\mathbf{2 8}$ to participate in enolate chemistry. Silyl protection of $\beta$-hydroxyketone $\mathbf{2 8}$ proceeded smoothly to deliver ketone $\mathbf{2 9}$ in $96 \%$ yield. The lithium enolate derived from 29 reacted with ethyl cyanoformate to provide $\beta$-ketoester $\mathbf{3 0}$ in $80 \%$ yield. ${ }^{29}$ To access the cyclic core of $\mathbf{1}$ from this functionality, we proposed two parallel strategies: i) alkene oxidative cleavage followed by aldol condensation or ii) a-methylenation with subsequent RCM. As these routes were pursued, however, it was quickly found that furan $\mathbf{3 0}$ was not compatible with standard oxidative cleavage conditions $\left(\mathrm{O}_{3}\right.$, Johnson-Lemieux, $\mathrm{RuCl}_{3}$, etc.), giving only complex mixtures or starting material decomposition. Turning to the metathesis strategy, we began investigating a-methylenation protocols. Using the conditions recently reported by Connell and coworkers, treatment of $\mathbf{3 0}$ with $(\mathrm{HCHO})_{\mathrm{n}}$ and diisopropylammonium trifluoroacetate ${ }^{30}$ afforded the undesired Diels-Alder adduct 31, effectively rendering our RCM approach unfeasible. These results cast doubt as to whether our proposed C2-furan approach would provide access to 1 . In addition, the problems encountered in attempted oxidative cleavage of ketoester 30 gave us concern as to whether a late-stage unmasking of C2-furan could be realized. With these data in hand, we turned our attention toward developing a route to 1 from an early-stage Mannich reaction.

\section{C2-Carbamate Approach}

Our strategy for direct installation of a protected amine at $\mathrm{C} 2$ was inspired by the work of Schaus and coworkers wherein cinchona alkaloids catalyzed 1,3-dicarbonyl Mannich addition to carbamoyl aldimines. Expansion to our system would involve a new class of nucleophile possessing a-ureido functionality (Scheme 6). ${ }^{25}$ Also crucial to the success of this method would be selection of the appropriately-protected imine electrophile. In the event, we proceeded with Cbz-protected cinnamyl imine $\mathbf{3 2}$ and began testing conditions for the Mannich reaction. Working first in the racemic series, the reaction of a-ureidodiketone 8 with imine 32 in the presence of catalytic quantities of Hünig's base delivered Mannich product ( \pm )-33 in $90 \%$ yield. With the feasibility of this bond construction established, focus turned to finding a suitable chiral catalyst for the reaction. An extensive screen of known Mannich reaction promotors ${ }^{31}$ revealed cinchonidine to be a superior catalyst, providing (+)-33 in nearly quantitative yield with 84:16 er. Upon trituration, crystalline racemic 33 could be removed by filtration, leaving highly enantioenriched (+)-33 in 70\% yield and 98:2 er. Unsure of the enantiomer's configuration, we proceeded with optimization of this route with racemic material.

From functionalized dicarbonyl $\mathbf{3 3}$, we turned towards assembly of the $\mathrm{C} 1 / \mathrm{C} 2 / \mathrm{C} 7$ stereotriad via symmetry-breaking reduction (Scheme 7). Referring to our previously optimized conditions in the $\mathrm{C} 2$-unsubstituted case, monoreduction of $\mathbf{3 3}$ with LTBA at $-35^{\circ} \mathrm{C}$ provided $\beta$-hydroxy ketone 34 in $72 \%$ yield with high diastereoselectivity ( $>10: 1$ 34: $\Sigma$ other diastereomers). Efforts to determine the relative configuration of this monoalcohol were hampered, however, when initial studies toward accessing a crystalline derivative proved unsuccessful. Turning to spectroscopic methods, ozonolysis of the styrene provided lactol 
derivative $\mathbf{3 5}$ from which nOesy analysis suggested the relative configuration of the $\mathrm{C} 1 / \mathrm{C} 2 /$ C7 stereotriad illustrated in Scheme 8.

\section{Stereochemical Analysis}

With this tentative structure in hand, we began to analyze the stereochemical outcome and its ramifications. For planning purposes, we included both enantiomeric series in this analysis based on the assumption that either could be accessible via the catalytic, asymmetric Mannich addition. $\beta$-Hydroxyketone (+)-34 is epimeric at $\mathrm{C} 2$ relative to pactamycin (1), a problem for which a solution was not immediately obvious in light of our projected metathesis-based synthetic plan. Alternatively, the enantiomeric form (-)-34 presents $\mathrm{C} 1$ and $\mathrm{C} 2$ in the correct pactamycin configuration, but is a product resulting from incorrect diastereotopic ketone site selectivity in the desymmetrization. Although this was a discouraging initial result, we retained some measure of confidence in our symmetrybreaking approach to $\mathbf{1}$ and began pursuing myriad strategies in parallel for the elaboration of diketone $\mathbf{3 3}$ to our desired reduction diastereomer.

We first pursued an exhaustive screen of reducing agents and conditions in hopes that reagent control would provide stereoselectivity different to that observed using LTBA. Monoreduction with a number of bulky hydride sources (L-Selectride ${ }^{\circledR}$, LDBBA, Red-Al@, DIBAL-H) resulted only in the formation of stereoisomer 34 in lower yields. Unhindered hydride sources $\left(\mathrm{LiAlH}_{4}\right.$, Super Hydride, $\left.\mathrm{NaBH}_{4}\right)$, gave only minimal amounts of 34 accompanied with retro-aldol decomposition pathways. Finally, alternative reduction pathways (enzymatic reduction, transfer hydrogenation) gave no promise for delivering diastereoselectivity different to that observed in LTBA reduction of diketone $\mathbf{3 4}$. These unsuccessful efforts led us to the conclusion that this reduction was proceeding with virtually complete substrate control, and as a result, direct reduction strategies of $\mathbf{3 3}$ towards the desired diastereomer were abandoned.

In an effort to alter the apparent conformational bias associated with the acyclic structure $\mathbf{3 3}$, the diketone was engaged as its derived cyclic iodoimidate $\mathbf{3 6}$ through the action of $\mathrm{I}_{2}$ and $\mathrm{Na}-\mathrm{HCO}_{3}$. Subsequent monoreduction of diketone 36 followed by retrocyclization (mediated by $\mathrm{Zn} / \mathrm{HOAc}$ ) gave the acyclic hydroxy ketone 37 in $61 \%$ yield over two steps. Ketone $\mathbf{3 7}$ is a diastereomer different from that accessed via LTBA reduction of $\mathbf{3 3}$. We immediately began work in establishing its stereochemical identity; however, nOesy analysis by a strategy analogous to that used for $\mathbf{3 4}$ was inconclusive.

Concurrent with these studies, we pursued an alternate strategy from the perspective of (-) -34. Namely, if the original monoreduction product could be further reduced to its corresponding diol (syn or anti), a site selective oxidation might deliver the desired C1/C2/ $\mathrm{C} 7$ configuration. To this end, a screen of conditions revealed that direduction of $\mathbf{3 3}$ with excess LDBBA afforded diol $\mathbf{3 8}$ as a 3:1 mixture of separable diastereomers. The major isomer was revealed to be the 1,3-trans diol via nOesy and ${ }^{13} \mathrm{C}$ NMR analysis of the derived acetonide $39 .{ }^{32}$ Control experiments revealed that this reduction proceeds via the intermediacy of $\beta$-hydroxyketone 34. Consequently, the relative stereochemistry at $\mathrm{C} 2$ was assigned according to that shown in alcohol $\mathbf{3 4}$.

With diol 38 in hand, we began evaluating oxidants for symmetry-breaking oxidation. Treating diol 38 with Dess-Martin periodinane (DMP) showed complete selectivity for oxidation of a single site, returning the original hydroxyketone 34 . Alternatively, tetrapropylammonium perruthenate (TPAP) gave preference for the opposite alcohol, delivering monoalcohol 37 whose spectral characteristics matched those of the compound prepared via the iodoimidate. The ability to access $\mathbf{3 7}$ from this route enabled us to assign its 
relative stereochemistry, which had previously remained ambiguous via nOesy analysis of its derivatives.

It is germane to emphasize at this juncture that the above analysis hinged in its entirety on the nOesy analysis of $\mathbf{3 5}$, which was suggestive of the illustrated structure, but not unequivocal. Because it was so easily accessible, we made the conscious decision to move forward in our synthetic plan with (+)-34 in the interest of evaluating the chemical viability of our remaining strategy, despite (or because of!) the absence of an unambiguous stereochemical assignment. It was our hope that rigorous stereochemical proof would be realized via a suitable crystalline derivative later in the route and that the chemistry developed during those studies could be effectively translated to whatever diastereomer was needed.

\section{Cyclopentane Core}

Silyl protection of (+)-34 under typical conditions proceeded smoothly, delivering $\beta$ silyloxy ketone $\mathbf{4 0}$ in $84 \%$ yield (Scheme 8). Carboethoxylation of $\mathbf{4 0}$ under the previously optimized conditions (cf. $\mathbf{2 9} \rightarrow \mathbf{3 0}$ ) proceeded uneventfully to deliver the corresponding ketoester in good yield; however, this intermediate could never be successfully advanced despite extensive efforts. ${ }^{33}$ Accordingly, we began to investigate routes by which we might directly install the requisite $\mathrm{C} 4$ hydroxymethylene in its correct oxidation state for elaboration to $\mathbf{1}$. This approach would deliver a less activated $\beta$-hydroxyketone for subsequent intramolecular condensation. Literature examples for the use of formaldehyde as an aldol electrophile in complex total synthesis are limited. Trost and coworkers have demonstrated its use in their synthesis of corianin. ${ }^{34}$ The Cao group likewise has shown the use of $\mathrm{CH}_{2} \mathrm{O}$ in aldol reactions en route to a total synthesis of malyngamide $\mathrm{U} .{ }^{35}$ After significant experimentation in our system, we found that bubbling gaseous $\mathrm{CH}_{2} \mathrm{O}$ (generated by the pyrolysis of paraformaldehyde) through a solution of the lithium enolate of $\mathbf{4 0}$ at -45 ${ }^{\circ} \mathrm{C}$ furnished the desired primary alcohol $\mathbf{4 1}$ in $70 \%$ yield. Subsequent styrene ozonolysis delivered the corresponding crude a-carbamoyl aldehyde $\mathbf{4 2}$ poised for intramolecular condensation. $\mathrm{NaOMe}$ emerged as a superior promoter from our screen of conditions, delivering cyclopentenone $\mathbf{4 3}$ in $50 \%$ yield from $\mathbf{4 1}$. This transformation was rendered completely ineffective if the C6 hydroxymethylene was protected. ${ }^{36}$ Fortunately, elimination of $\mathrm{H}_{2} \mathrm{O}$ strongly favors the formation of the endocyclic alkene over its constitutional isomer, the a-methylidene cyclopentanone.

With cyclopentenone $\mathbf{4 3}$ in hand, only C5 nucleophilic addition, C4 hydroxylation, and installation of the $\mathrm{C} 3$ aniline remained to complete the core structure of $\mathbf{1}$. An epoxidation/ nucleophilic aniline ring-opening sequence was pursued to access the trans-anilinoalcohol, inspired by a related approach by Hanessian and coworkers. ${ }^{9,10}$ We surmised that addition of a suitable methide nucleophile to the C5 ketone would install the final stereogenic center. Our experiments revealed that the order of these steps and the identity of the C6 hydroxymethylene protecting group were critical. Thus, treatment of enone $\mathbf{4 3}$ with $\mathrm{NaOH} /$ $\mathrm{H}_{2} \mathrm{O}_{2}$ delivered epoxy-alcohol $\mathbf{4 4}$ in $80 \%$ yield with high diastereoselectivity. As in the case of the intramolecular aldol condensation $(\mathbf{4 2} \rightarrow \mathbf{4 3})$, the reaction was ineffective if the C6 hydroxyl was protected. We then turned our attention to installation of the $\mathrm{C} 5$ methyl group. In the event, the sterically-demanding TBDPS group ${ }^{37}$ was found to be necessary to provide the desired stereoselectivity and withstand the reaction conditions for nucleophilic addition. Protection of $\mathbf{4 4}$ occurred uneventfully to provide TBDPS-ether $\mathbf{4 5}$ in $76 \%$ yield and treating this ketone with $\mathrm{MeMgBr}$ at $0{ }^{\circ} \mathrm{C}$ provided alcohol 46 (diastereoselection >10:1).

\section{Stereochemical Outcome}

Having arrived at an intermediate bearing all six of pactamycin's stereocenters, we began aggressively pursuing a crystalline intermediate to confirm (or disprove) our earlier 
stereochemical analyses. Carboxybenzyl deprotection of $\mathbf{5 3}$ occurred under hydrogenolysis conditions to deliver the corresponding primary amine, which crystallized readily (Figure 2). $\mathrm{X}$-ray analysis of this derivative confirmed the desired relative stereochemistry at all six centers.

This surprising confirmation of correct stereochemistry led us to a number of conclusions regarding the observed results. With regard to the C5-methylation, nucleophile addition to the convex surface of similar oxabicyclo[3.1.0] hexanone systems is well documented; in our system, this trajectory would have delivered the incorrect C5 configuration (Scheme 9).

Indeed, Hanessian and coworkers witnessed exclusively convex surface addition of a methide nucleophile to ketone $\mathbf{4 7}$ in their total synthesis of $\mathbf{1 . 9 , 1 0}$ A five-step sequence from 48 provided the correct epoxide stereochemistry for synthesis completion. Greaney and coworkers likewise observed this facial preference in the addition of an alkyllithium nucleophile to ketone $\mathbf{4 9}$ in their syntheses of merrilactone A and anislactone A. ${ }^{38}$ In our system, however, this inherent preference was seemingly overridden, delivering the desired stereochemistry at C5. In the present case, we speculate that this selectivity is observed at least in part due to direction by the C1-dimethylurea, providing additional support to the decision to incorporate this functionality in its native form early in the synthesis. Furthermore, the presence of two large silyl groups on the convex face of epoxide $\mathbf{4 5}$ might serve to block the undesired facial approach.

The presence of the desired $\mathrm{C} 1 / \mathrm{C} 2 / \mathrm{C} 7$ stereotriad in $\mathbf{4 6}$ seemed at odds with our original stereochemical assignment of hydroxyketone $\mathbf{3 4}$ based on nOesy analysis of lactol derivative 35; however, conscious of the fact that the $\mathrm{C} 2$ stereocenter had potentially become configurationally labile in the form of aldehyde 42 , we questioned whether epimerization had taken place during base-promoted condensation to deliver the desired $\mathrm{C} 2$ configuration. We devised a deuterium labeling experiment to examine the possibility of this pathway (Scheme 10).

Treating a-carbamoyl aldehyde $\mathbf{4 2}$ with $\mathrm{NaOMe}$ in $\mathrm{CD}_{3} \mathrm{OD}$ using the optimized conditions afforded enone $\mathbf{4 3}$ with complete incorporation of deuterium at $\mathrm{C} 2$. When this experiment was conducted at $-10{ }^{\circ} \mathrm{C}$ for the same time duration, a complex mixture of products was observed by ${ }^{1} \mathrm{H}$ NMR spectroscopy. Resubmission of this unpurified complex mixture to the reaction conditions at $0{ }^{\circ} \mathrm{C}$ afforded enone 43 with complete D-incorporation. Finally, submission of the product enone $\mathbf{4 3}$ to $\mathrm{NaOMe}$ in $\mathrm{CD}_{3} \mathrm{OD}$ returned the starting material with no deuterium incorporation. These results clearly indicate that the $\mathrm{C} 2$ methine was undergoing proton exchange prior to the condensation; however, unambiguous confirmation of epimerization required X-ray analysis of an upstream intermediate. Returning to our previous attempts at derivatization of hydroxyketone (+)-34 led to the synthesis of enantioenriched benzoate derivative 51, which crystallized readily. X-ray analysis of $\mathbf{5 1}$ established the sense of induction in the asymmetric Mannich addition and confirmed the existence of the incorrect $C 2$ configuration in the desymmetrization product 34 . In light of this result, we speculate that formation of the observed monoreduction diastereomer $\mathbf{3 4}$ arises via the chelated structure $\mathbf{5 2}$, a proposal modeled after a similar case reported by Davis and co-workers (Scheme 11). ${ }^{39}$ Preferential $r e$-face addition of hydride to pseudochair conformer $\mathbf{5 2}$ gives rise to the observed monoreduction diastereomer.

From the complete set of experiments relating to the pactamycin stereochemistry problem, the following conclusions can be made (Scheme 12): i) our original stereochemical assignment of hydroxyketone $\mathbf{3 4}$ via nOesy analysis of $\mathbf{3 5}$ was correct; ii) the enantioselective Mannich addition $(\mathbf{8} \rightarrow \mathbf{3 3}$ ) had yielded the incorrect enantiomer nominally required for elaboration to $\mathbf{1}$; and iii) this stereochemical "mistake", compulsory for 
directing the correct $\mathrm{C} 1 / \mathrm{C} 7$ stereochemistry in the symmetry-breaking reduction $(\mathbf{3 3} \rightarrow \mathbf{3 4})$, was later corrected via epimerization in the aldol condensation $(\mathbf{4 2} \rightarrow \mathbf{4 3})$. Incredibly, this series of events had taken place unbeknownst to us until crystallographic evidence of a much later intermediate led us to suspect the validity of our original stereochemical analysis.

\section{Completion of Synthesis}

Our plan to complete the synthesis began with the development of a Lewis acid-promoted aniline epoxide opening to install the required $m$-acetylaniline in 1. A similar approach had been employed by Hanessian and coworkers for introduction of the $\mathrm{C} 3 / \mathrm{C} 4$ transanilinoalcohol whereupon the requisite aniline was incorporated via its $m$-propenyl derivative. ${ }^{9,10}$ The necessary acetophenone was later revealed via oxidative cleavage of the olefin. By contrast, we hoped that the required aniline could be installed in its native form, obviating downstream introduction of the ketone. After considerable experimentation, we found that addition of $m$-acetylaniline to epoxide $\mathbf{4 6}$ promoted by $\operatorname{Sc}(\mathrm{OTf})_{3}$ delivered the desired trans-aminoalcohol $\mathbf{5 3}$ in $66 \%$ yield. It is important to note that while this transformation proceeds in moderate yield, the use of more electron-rich anilines in the reaction delivers the corresponding epoxide-opened products in high yield, a valuable result as this step is a crucial branch point for analog synthesis. Silyl deprotection proceeded readily upon treatment of $\mathbf{5 3}$ with tetrabutylammonium fluoride (TBAF), providing tetraol $\mathbf{5 4}$ in $90 \%$ yield. Installation of the salicylate moiety was accomplished via treatment of alcohol 54 with an in-situ generated ketene electrophile derived from cyanomethylester 55. ${ }^{40}$ This left only removal of the $\mathrm{C} 2$ protecting group to complete our synthesis. Cbzdeprotection was effected readily upon hydrogenation of $\mathbf{5 6}$ in the presence of Pearlman's catalyst to deliver pactamycin (1) in $82 \%$ yield. $^{41}$

\section{CONCLUSION}

In summary, we have detailed the entirety of our efforts toward the synthesis of pactamycin, culminating in an asymmetric, 15 -step total synthesis in $1.9 \%$ overall yield from commodity chemical 2,4-pentanedione. Emphasis was placed on incorporation of all unique functionality (dimethylurea, aniline, salicylate) in its native form for minimization of protecting group manipulations. Revision of our originally published strategy led to the development of a novel alkylative cyclization for intramolecular delivery of C5 stereochemistry. A need to incorporate $\mathrm{C} 2$ functionality early-stage gave rise to the synthesis of a new difurylidene acetate reagent which was employed in a complex Tsuji-Trost allylation, and an enantioselective Mannich addition of a-ureidodicarbonyls was developed via an adaptation of the Schaus conditions. ${ }^{25}$ A symmetry-breaking reduction was employed for rapid delivery of the $\mathrm{C} 1 / \mathrm{C} 2 / \mathrm{C} 7$ stereotriad in 1, and proposed stereochemical models for these reductions are presented herein. In the case of the $\mathrm{C} 2$-carbamate approach, a thorough analysis of monoreduction stereochemical outcomes is presented. These studies culminated with the conclusion that selective oxidation of trans-diol $\mathbf{3 8}$ could allow access to a suitable monoreduction diastereomer of $\mathbf{3 3}$ for elaboration to $\mathbf{1}$. This deduction directed the decision to move forward in our strategy without unambiguous stereochemical confirmation of alcohol $\mathbf{3 4}$ with the assumption that the necessary relative configuration of $\mathbf{1}$ could be realized later in the synthesis. The stereochemical identity of $\mathbf{3 4}$ was later unambiguously determined to be incorrect at $\mathrm{C} 2$, although this "stereochemical error" was corrected via epimerization during a downstream aldol condensation. This fortuitous turn of events allowed facile access to $\mathbf{1}$ in the absence of non-strategic stereochemical manipulations. This route is flexible and immediately amenable to the synthesis of structural analogs as major functional groups (aniline, salicylate) are incorporated in a late-stage fashion. Studies towards the preparation of analogs for analysis of structure-activity relationships (SAR) are ongoing in our laboratory and will be reported in due course. 


\section{Supplementary Material}

Refer to Web version on PubMed Central for supplementary material.

\section{Acknowledgments}

The project described was supported by Award No. R01 GM084927 from the National Institute of General Medical Sciences. R.J.S acknowledges an NSF Graduate Research Fellowship. J.T.M. acknowledges an ACS Division of Organic Chemistry graduate fellowship. X-ray crystallography was performed by Dr. Peter White (UNC). CCDC 914582, 959045, and 959046 contain the supplementary crystallographic data for this paper. These data can be obtained free of charge from The Cambridge Crystallographic Centre via www.ccdc.cam.ac.uk/data_request/cif.

\section{REFERENCES}

1. (a) Nicolaou, KC.; Sorensen, EJ. Classics in Total Synthesis. VCH; New York: 1996. (b) Nicolaou, KC.; Snyder, SA. Classics in Total Synthesis II. VCH; New York: 2003.

2. Argoudelis AD, Jahnke HK, Fox JA. Antimicrob. Agents Chemother. 1962:191.

3. (a) Weller DD, Haber A, Rinehart KL, Wiley PF. J. Antibiot. 1970; 31:997. [PubMed: 711622] (b) Wiley PF, Jahnke HK, MacKellar FA, Kelly RB, Argoudelis AD. J. Org. Chem. 1970; 35:1420. [PubMed: 5440331]

4. (a) Dinos G, Wilson DN, Teraoka Y, Szaflarski W, Fucini P, Kalpaxis D, Nierhaus KH. Mol. Cell. 2004; 13:113. [PubMed: 14731399] (b) Carter AP, Clemons WM Jr. Brodersen DE, MorganWarren RJ, Wimberly BT, Ramakrishnan V. Nature. 2000; 407:340. [PubMed: 11014183]

5. (a) Otogouro K, Iwatsuki M, Ishiyama A, Namatame M, Nishihara-Tukashima A, Shibahara S, Kondo S, Yamada H, Ōmura S. J. Antibiot. 2010; 63:381. [PubMed: 20661239] (b) Lu W, Roongsawang N, Mahmud T. Chem.Biol. 2011; 18:425. [PubMed: 21513878]

6. (a) Almabruk KH, Lu W, Li Y, Abugreen M, Kelly JX, Mahmud T. Org. Lett. 2013; 15:1678. [PubMed: 23521145] (b) Iwatsuki M, Nishihara-Tsukashima A, Ishiyama A, Namatame M, Watanabe Y, Handasah S, Pranamuda H, Marwoto B, Matsumoto A, Takahashi Y, Otoguro K, Ōmura S. J. Antibiot. 2012; 65:169. [PubMed: 22234298] (c) Lu W, Roongsawang N, Mahmud T. Chem. Biol. 2011; 18:425. [PubMed: 21513878] (d) Otogouro K, Iwatsuki M, Ishiyama A, Namatame M, Nishihara-Tukashima A, Shibahara S, Kondo S, Yamada H, Ōmura S. J. Antibiot. 1986; 63:381.(e) Dobashi K, Isshiki K, Sawa T, Obata T, Hamada M, Naganawa H, Takita T, Takeuchi T, Umezawa H. J. Antibiot. 1986; 39:1779. [PubMed: 3818452]

7. (a) Hanessian S, Vatiki RR, Chattopadhyay AK, Dorich S, Lavallée C. Bioorg. Med. Chem. 2013; 21:1775. [PubMed: 23434136] (b) Tourigny DS, Fernández IS, Kelley AC, Vakiti RR, Chattopadhyay AK, Dorich S, Hanessian S, Ramakrishnan V. J. Mol. Biol. 2013; 425:3907. [PubMed: 23702293]

8. Duchamp DJ. Abstracts, American Crystallographic Association Winter Meeting; Albuquerque, NM. 1972:23.

9. Hanessian S, Vakiti RR, Dorich S, Banerjee S, Lecomte F, Del Valle JR, Zhang J, DeschênesSimard B. Angew. Chem. Int. Ed. 2011; 50:3497.

10. Hanessian S, Vakiti R, Dorich S, Banerjee S, Deschênes-Simard B. J. Org. Chem. 2012; 77:9458. [PubMed: 23083207]

11. Tsujimoto T, Nishikawa T, Urabe D, Isobe M. Synlett. 2005:433.

12. Knapp S, Yu Y. Org. Lett. 2007; 9:1359. [PubMed: 17338541]

13. Haussener TJ, Looper RE. Org. Lett. 2012; 14:3632.

14. Matsumoto N, Tsujimoto T, Nakazaki A, Isobe M, Nishikawa T. RSC Adv. 2012; 2:9448.

15. Malinowski JT, McCarver SJ, Johnson JS. Org. Lett. 2012; 14:2878. [PubMed: 22617016]

16. Burns NZ, Baran PS, Hoffmann RW. Angew. Chem. Int. Ed. 2009; 48:2854.

17. Science. 2013; 340:180. [PubMed: 23580525]

18. Kuwano R, Ito Y. J. Am. Chem. Soc. 1999; 121:3236.

19. Magnuson SR. Tetrahedron. 1995; 51:2167.

20. Baum JS, Shook DA, Davies HML, Smith HD. Synth. Commun. 1987; 17:1709. 
21. Lee SH, Yoshida K, Matsushita H, Clapham B, Koch G, Zimmermann J, Janda KD. J. Org. Chem. 2004; 69:8829. [PubMed: 15575764]

22. Crimmins MT, Mascarella SW, DeLoach JA. J. Org. Chem. 1984; 49:3033.

23. 2-Butynoic acid was used due to low yields associated with esterification of $\mathbf{1 7}$ with propynoic acid.

24. Schmid G, Fukuyama T, Akasaka K, Kishi Y. J. Am. Chem. Soc. 1979; 101:259.

25. (a) Lou S, Taoka BM, Ting A, Schaus SE. J. Am. Chem. Soc. 2005; 127:11256. [PubMed: 16089450] (b) Ting A, Lou S, Schaus SE. Org. Lett. 2006; 8:2003. [PubMed: 16671767]

26. (a) Paxton RJ, Taylor RJK. Synlett. 2007; 4:633.(b) Mamaghani M, Mahmoodi NO, Moghisseh AA, Pourmohamad L. J. Iran. Chem. Soc. 2008; 5:238.

27. See the Supporting Information.

28. Kim MS, Choi YM, An DK. Tetrahedron Lett. 2007; 48:5061.

29. Crabtree SR, Chu WLA, Mander LN. Synlett. 1990:169.

30. Bugarin A, Jones KD, Connell BT. Chem. Commun. 2010; 46:1715.

31. See the Supporting Information for a complete list of catalysts screened

32. Rychnovsky SD, Skalitzky DJ. Tetrahedron Lett. 1990; 31:945.

33. a-Methylenation protocols toward an RCM strategy gave only starting material decomposition. Ozonolysis provided the corresponding crude a-carbamoyl aldehyde necessary for intramolecular condensation, but this aldehyde was ultimately too reactive to participate in productive chemistry. See the Supporting Information for experimental details.

34. Trost BM, Haffner CD, Jebaratnam DJ, Krische MJ, Thomas AP. J. Am. Chem. Soc. 1999; 121:6183.

35. Li Y, Feng J-P, Wang W-H, Chen J, Cao X-P. J. Org. Chem. 2007; 72:2344. [PubMed: 17346080]

36. Verlaak JMJ, Klunder AJH, Zwanenburg B. Tetrahedron Lett. 1982; 23:5463.

37. Lavallee P, Hanessian S. Can. J. Chem. 1975; 53:2975.

38. (a) Shi L, Meyer K, Greaney MF. Angew. Chem. Int. Ed. 2010; 49:9250.(b) Myers AG, Glatthar R, Hammond M, Harrington PM, Kuo EY, Liang J, Schaus SE, Wu Y, Xiang J-N. Intermediate diastereoselectivity has also been observed in the oxabicyclo[3.1.0]hexanone system. J. Am. Chem. Soc. 2002; 124:5380. [PubMed: 11996579]

39. Davis FA, Gaspari PM, Nolt BM, Xu P. J. Org. Chem. 2008; 73:9619. [PubMed: 18986203]

40. Shen R, Lin CT, Bowman EJ, Bowman BJ, Porco JA Jr. Org. Lett. 2002; 4:3103. [PubMed: 12201727]

41. Pearlman WM. Tetrahedron Lett. 1967; 8:1663. 

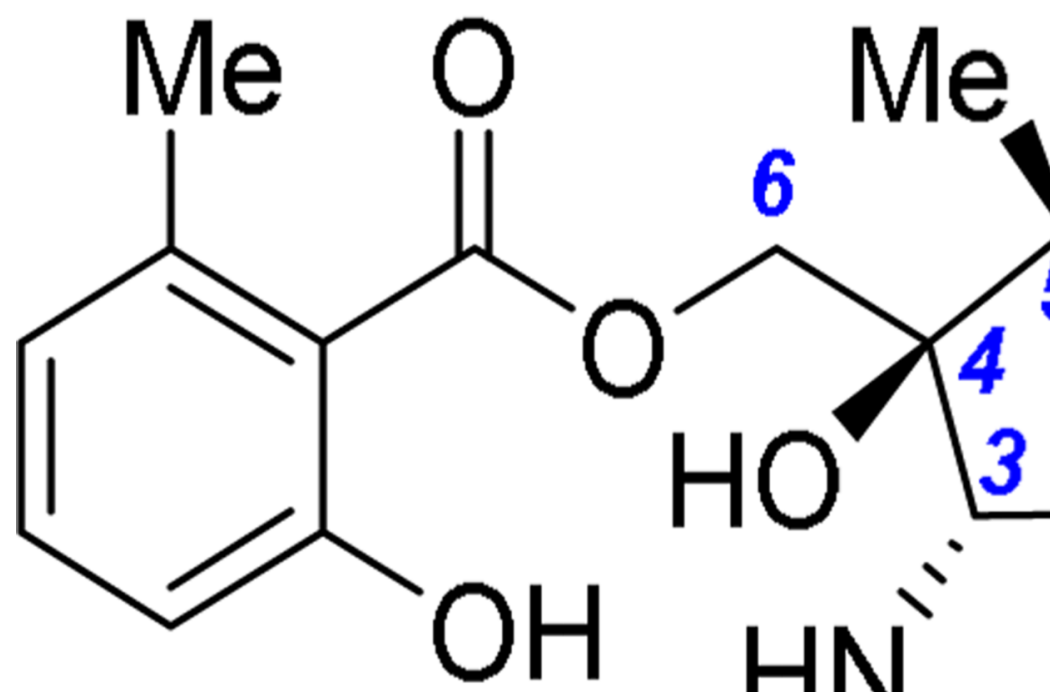<smiles>O[Hg]O</smiles>

Figure 1.

Pactamycin (1) 


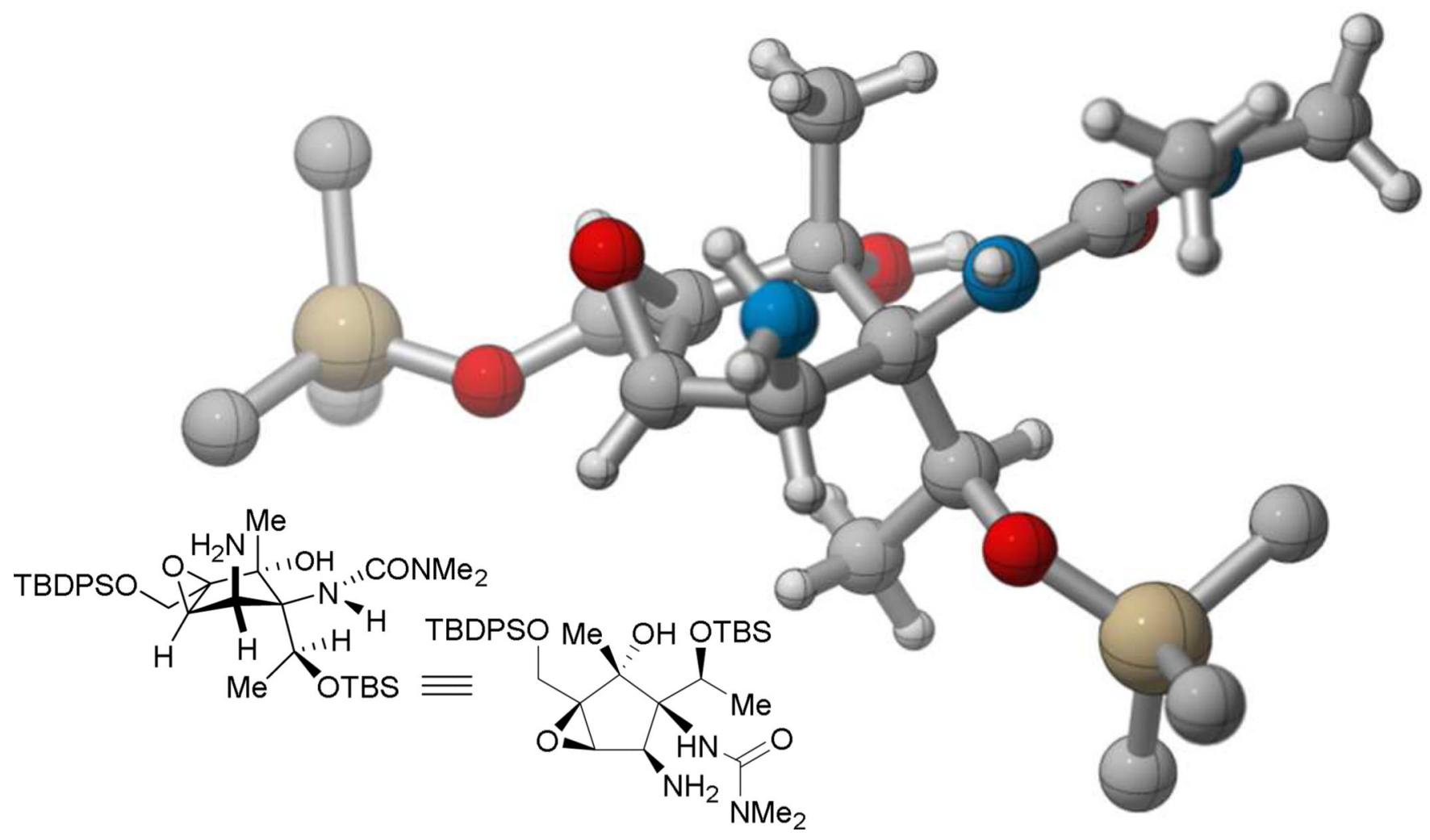

Figure 2.

$\mathrm{X}$-ray structure of Cbz-deprotected 46; the silyl groups are truncated for clarity. Disorder exists in the TBS group. 


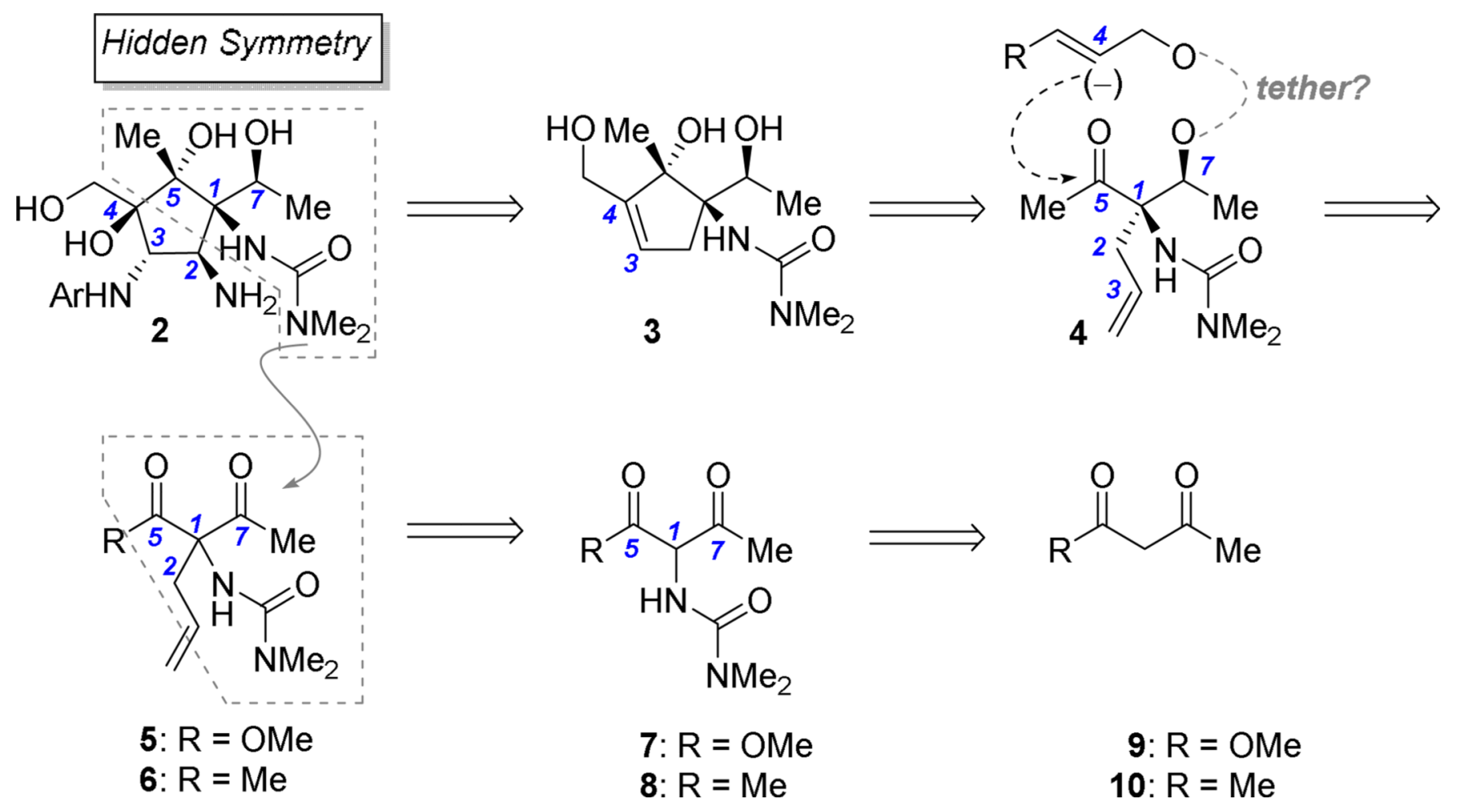

Scheme 1.

Initial retrosynthetic analysis for pactamycin 


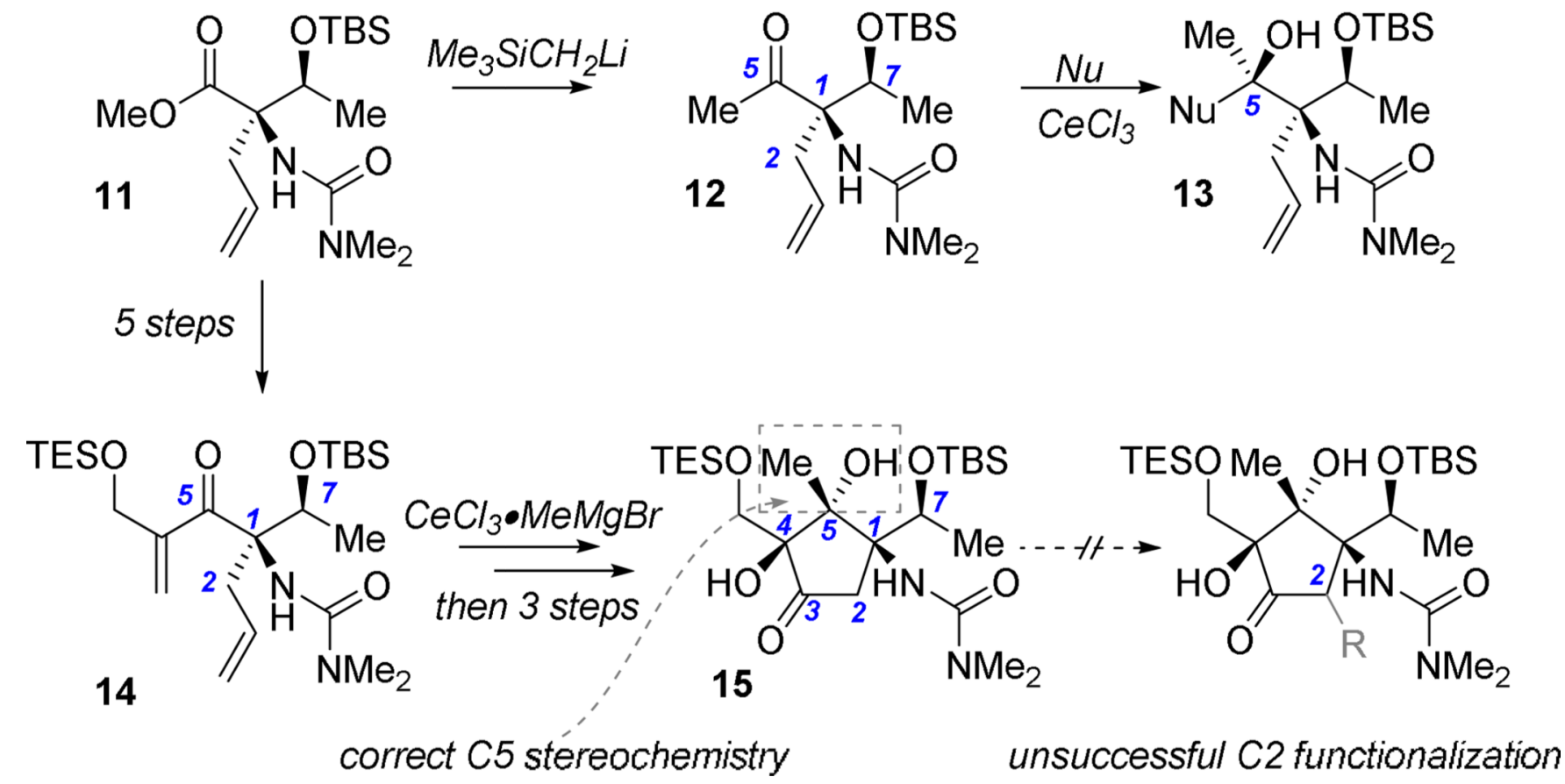

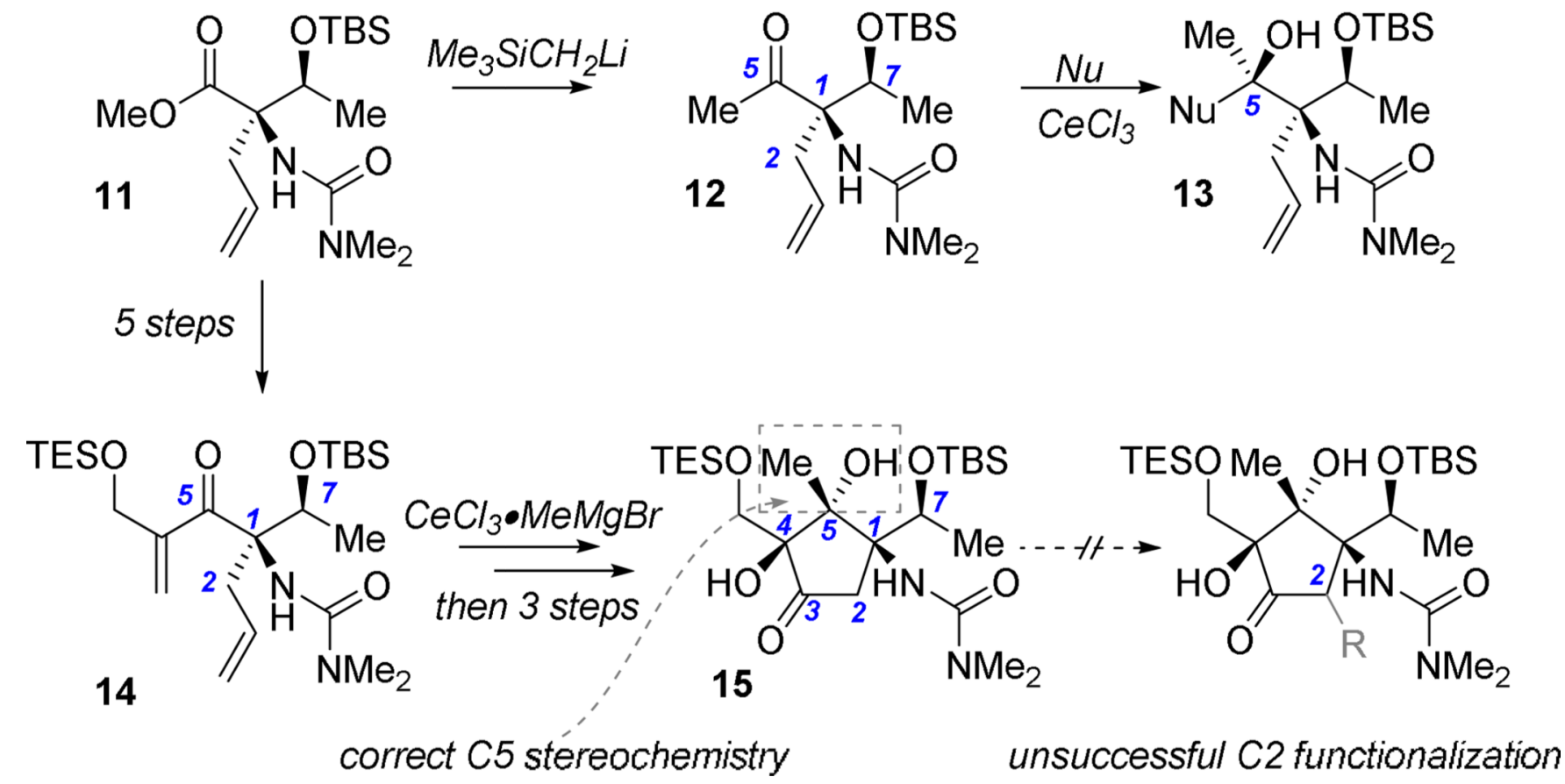

incorrect C5 stereochemistry

Scheme 2.

Previously reported intermolecular addition approach to 1 
<smiles>CC(=O)CC(C)=O</smiles><smiles>C=CCC(NC(N)=O)(C(C)=O)C(C)=O</smiles>

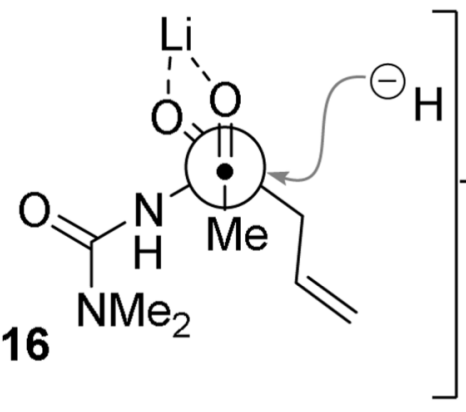<smiles>[Y6][C@H](O)[C@@](CC=C)(NC(N)=O)C(C)=O</smiles><smiles>C=CC[C@](NC(N)=O)(C(C)=O)[C@@H](C)OC(=O)C#CC</smiles><smiles>[M]OC(=CC)O[C@H](C)[C@@](CC=C)(NC(=O)N(C)C)C(C)=O</smiles>

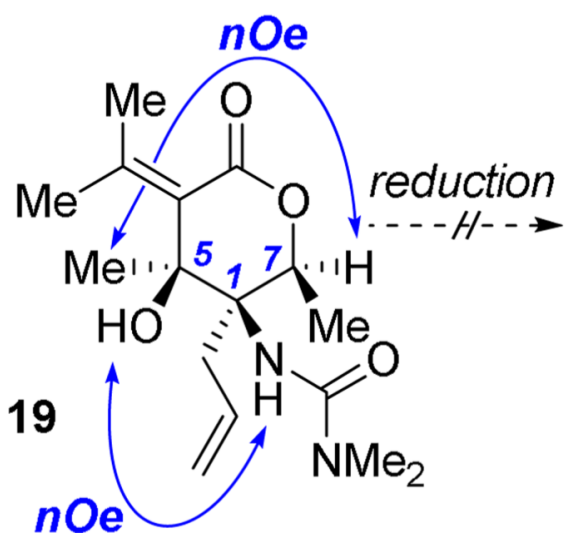<smiles>C=CC[C@](NC(N)=O)([C@H](C)O)[C@](O)(C(CO)=C(C)C)[C@@H](C)O</smiles>

Scheme 3.

Intramolecular addition approach to $15 \mathrm{a}$

${ }^{a}$ Conditions: (a) pABSA, $\mathrm{Et}_{3} \mathrm{~N}, \mathrm{CH}_{3} \mathrm{CN}$; $0{ }^{\circ} \mathrm{C}$ to rt; (b) $\mathrm{Rh}_{2} \mathrm{Oct}_{4}(0.4 \mathrm{~mol} \%), 1,1-$ dimethylurea, $\mathrm{C}_{7} \mathrm{H}_{8} / \mathrm{DCE}(1: 1), 80^{\circ} \mathrm{C}$; (c) [allylPdCl] 2 (0.5 mol \%), rac-BINAP (1.1 mol $\%),{ }^{t} \mathrm{BuOK}$, allyl acetate, $\mathrm{C}_{7} \mathrm{H}_{8}, \mathrm{rt}$; (d) $\mathrm{LiAl}\left(\mathrm{O}^{t} \mathrm{Bu}\right)_{3} \mathrm{H}$, THF, $-40{ }^{\circ} \mathrm{C}$; (e) 2-butynoic acid, DMAP (10 mol \%), DIC, $\mathrm{Et}_{2} \mathrm{O},-20{ }^{\circ} \mathrm{C}$ to rt; (f) $\mathrm{Me}_{2} \mathrm{CuLi}, \mathrm{Et}_{2} \mathrm{O},-78{ }^{\circ} \mathrm{C}$ to rt. 


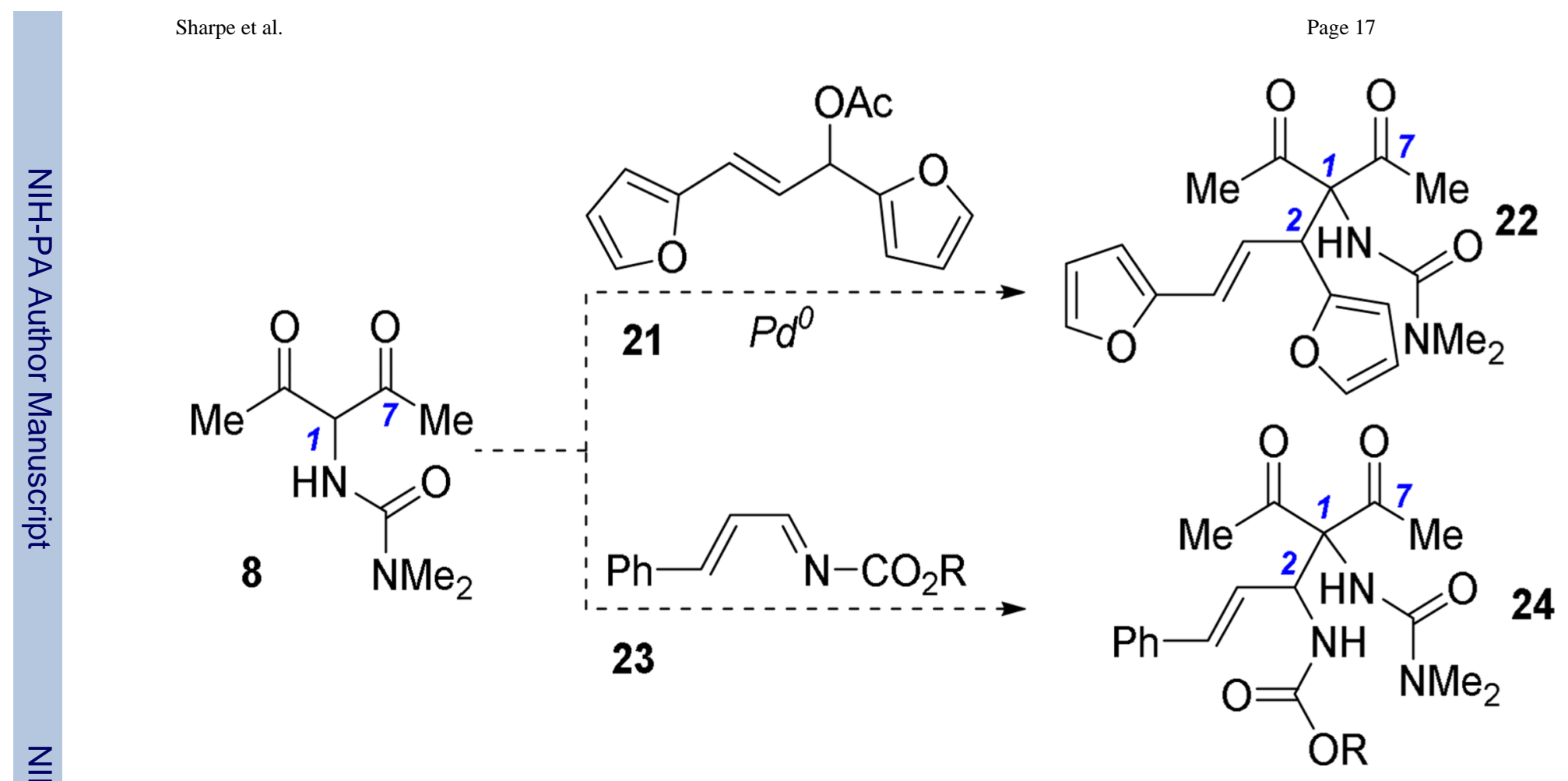

Scheme 4.

Proposed routes to $\mathrm{C} 2$-functionalized desymmetrization precursors 


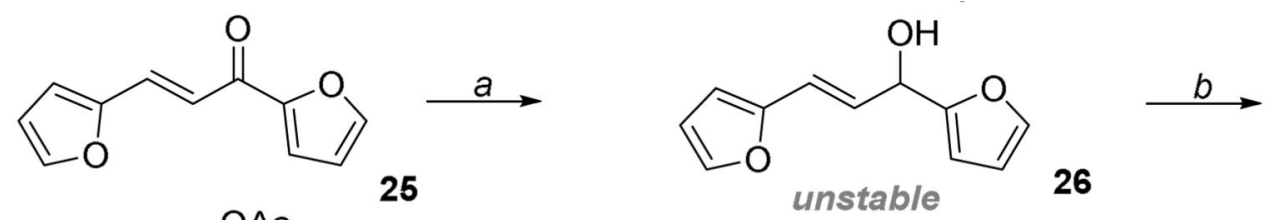<smiles>CC(=O)NC(C(C)=O)C(C)=O</smiles><smiles>CC(=O)NC(C(C)=O)(C(C)=O)[C@H](/C=C/c1ccco1)c1ccco1</smiles>

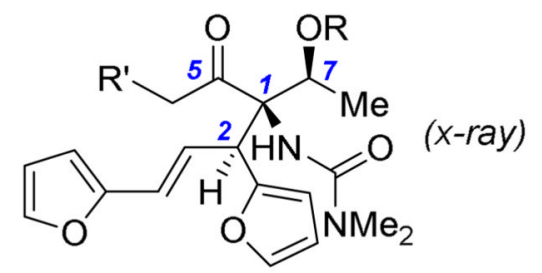

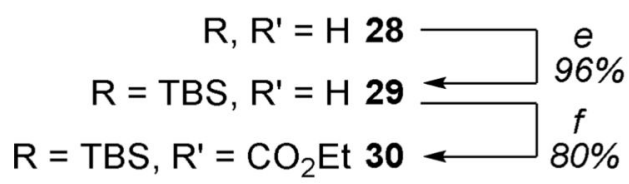

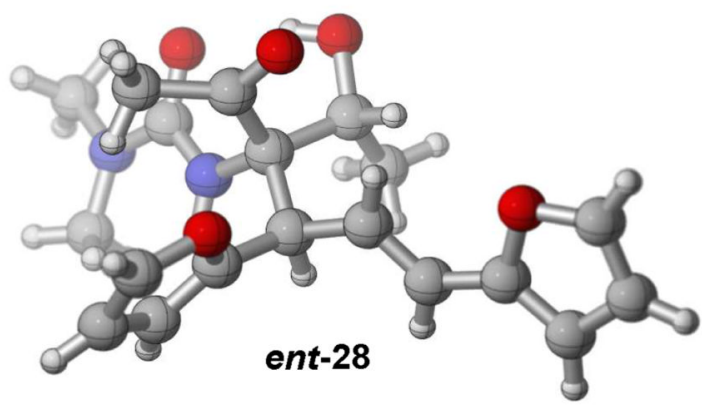

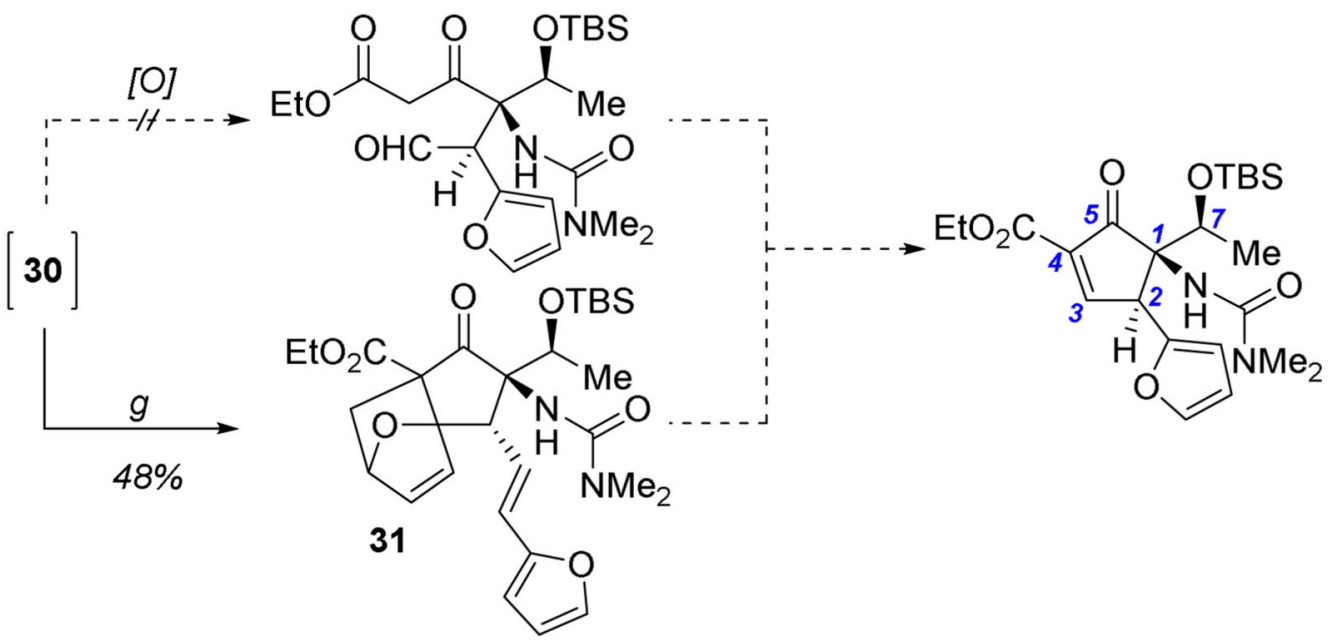

Scheme 5.

Desymmetrization of 2-furyl substituted diketone derivative 27 and advancement toward the synthesis of 1a

${ }^{a}$ Conditions: (a) $\mathrm{NaBH}_{4}, \mathrm{THF}: \mathrm{H}_{2} \mathrm{O}$ (1:1), rt; (b) $\mathrm{Ac}_{2} \mathrm{O}, \mathrm{NEt}_{3}$, DMAP (5 mol \%), $\mathrm{Et}_{2} \mathrm{O}$, rt; (c) [allylPdCl] $]_{2}\left(2.5 \mathrm{~mol} \%\right.$ ), rac-BINAP (5.28 mol \%), ${ }^{t} \mathrm{BuOK}, \mathrm{C}_{7} \mathrm{H}_{8}, \mathrm{rt}$; (d) $\mathrm{LiAl}\left(\mathrm{O}^{t} \mathrm{Bu}\right)$

$\left({ }^{i} \mathrm{Bu}\right)_{2} \mathrm{H}$, THF, $-78{ }^{\circ} \mathrm{C}$; (e) TBSCl, imidazole, $\mathrm{CH}_{2} \mathrm{Cl}_{2}$, rt; (f) LDA, THF, $-78{ }^{\circ} \mathrm{C}$, then ethyl cyanoformate, $-78{ }^{\circ} \mathrm{C}$ to $-20^{\circ} \mathrm{C} ;(\mathrm{g})$ diisopropylammonium trifluoroacetate, $(\mathrm{HCHO})_{\mathrm{n}}$, THF, $65^{\circ} \mathrm{C}$. 
<smiles>CC(=O)NC(C(C)=O)C(C)=O</smiles>

32

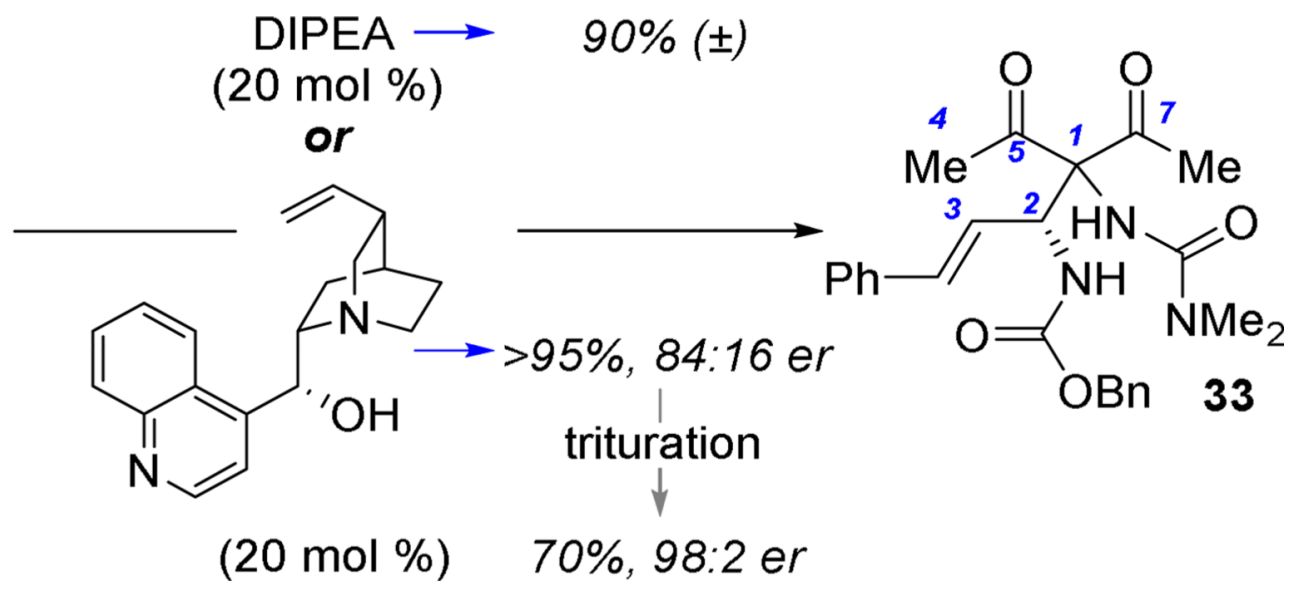

Scheme 6.

Development of a Mannich reaction for installation of C2 functionality 


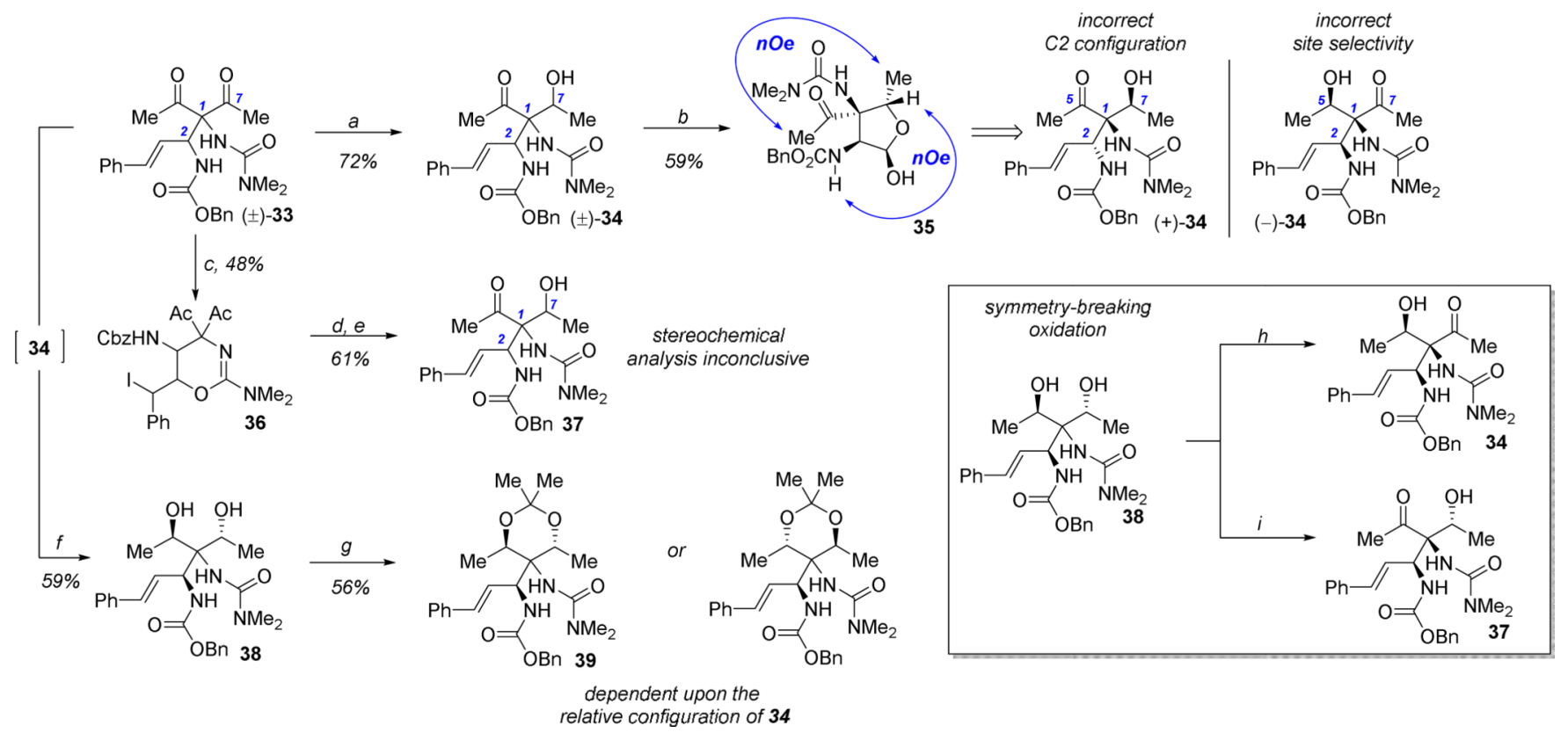

Scheme 7.

Studies on symmetry-breaking reduction of 33a

${ }^{a}$ Conditions: (a) LTBA, THF, $-35^{\circ} \mathrm{C}$; (b) $\mathrm{O}_{3}, \mathrm{CH}_{2} \mathrm{Cl}_{2},-78$; $\mathrm{Me}_{2} \mathrm{~S}$, rt; (c) $\mathrm{I}_{2}, \mathrm{NaHCO}_{3}, 4 \AA$ MS, $0{ }^{\circ} \mathrm{C}$ to rt; (d) LTBA, THF, $-10{ }^{\circ} \mathrm{C}$; (e) $\mathrm{Zn}, \mathrm{AcOH}, \mathrm{Et}_{2} \mathrm{O}: \mathrm{MeOH}(1: 1)$, rt; (f) LDBBA, $\mathrm{C}_{7} \mathrm{H}_{8},-40{ }^{\circ} \mathrm{C}$; (g) CSA, acetone:dimethoxypropane (1:1), rt; (h) DMP, $\mathrm{CH}_{2} \mathrm{Cl}_{2}$, rt; (i) TPAP, $\mathrm{CH}_{3} \mathrm{CN},-20{ }^{\circ} \mathrm{C}$. 


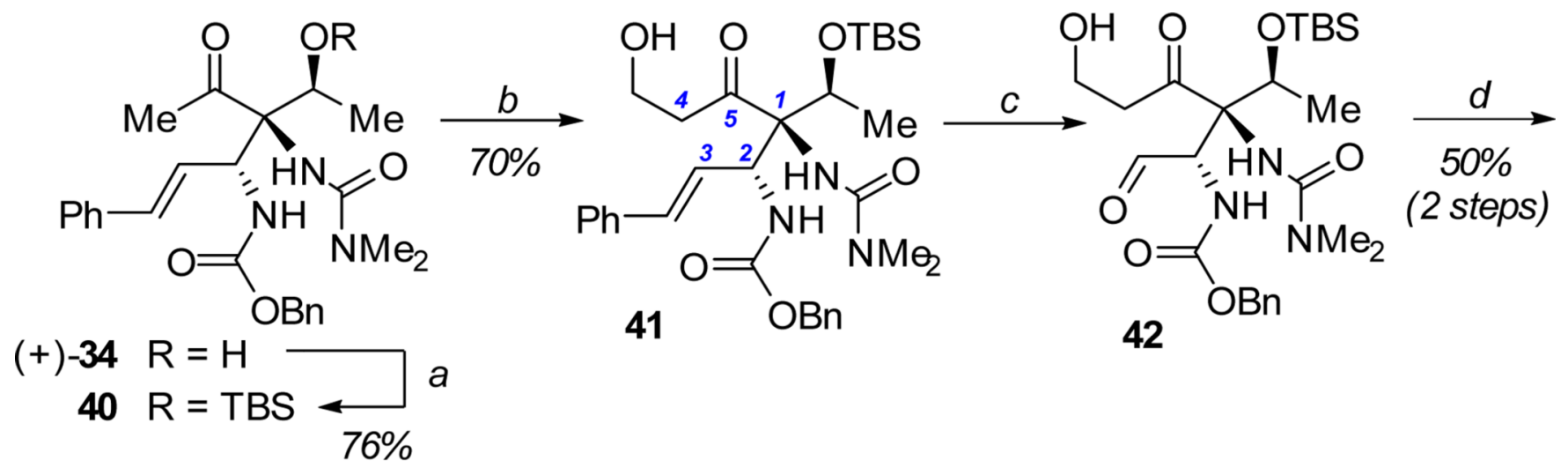

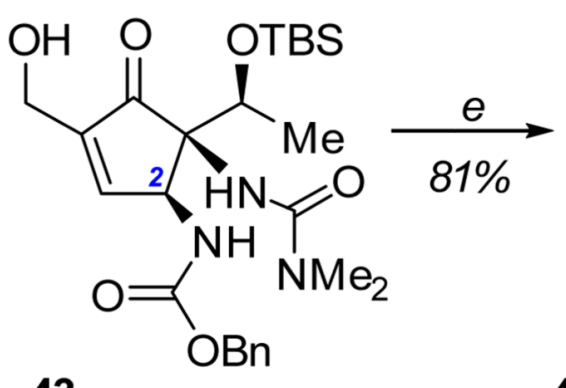

43<smiles>[R]C[C@]12O[C@H]1[C@H](NC(=O)OCc1ccccc1)[C@@](NC(=O)N(C)C)([C@H](C)[OH+])C2=O</smiles>

$\begin{array}{ll}44 & \mathrm{R}=\mathrm{H} \\ 45 & \mathrm{R}=\text { TBDPS } \\ & \end{array}$
46<smiles>C[C@H]([OH2+])[C@]1(O)[C@H](NC(=O)OCc2ccccc2)[C@H]2O[C@]2(C)[C@@]1(C)CO</smiles>

$x$-ray

(des-Cbz derivative)

Scheme 8.

Access to cyclopentane core via formaldehyde aldol/condensationa ${ }^{a}$ Conditions: (a) TBSOTf, 2,6-lutidine, $\mathrm{CH}_{2} \mathrm{Cl}_{2},-78{ }^{\circ} \mathrm{C}$; (b) LDA, THF, $-78{ }^{\circ} \mathrm{C}$, then $\mathrm{CH}_{2} \mathrm{O}_{(g)},-45^{\circ} \mathrm{C}$; (c) $\mathrm{O}_{3},-78^{\circ} \mathrm{C}, \mathrm{CH}_{2} \mathrm{Cl}_{2} ; \mathrm{Me}_{2} \mathrm{~S}$, rt; (d) NaOMe, THF:MeOH (4:1), $0{ }^{\circ} \mathrm{C}$; (e) $\mathrm{H}_{2} \mathrm{O}_{2}$ (30\% aq.), $\mathrm{NaOH}\left(20 \%\right.$ aq.), $\mathrm{MeOH}: \mathrm{CH}_{2} \mathrm{Cl}_{2}$ (7:1), $0^{\circ} \mathrm{C}$; (f) $\mathrm{TBDPSCl} \mathrm{NEt}_{3}$, DMAP (10 mol \%), $\mathrm{CH}_{2} \mathrm{Cl}_{2}, 0{ }^{\circ} \mathrm{C}$ to rt; (g) $\mathrm{MeMgBr}$, THF, $0{ }^{\circ} \mathrm{C}$. 
- Hanessian, ref. 9

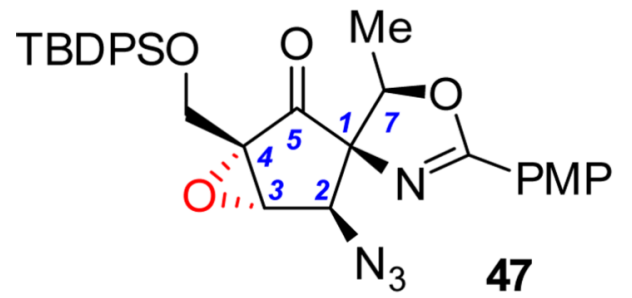

- Greaney, ref. 38

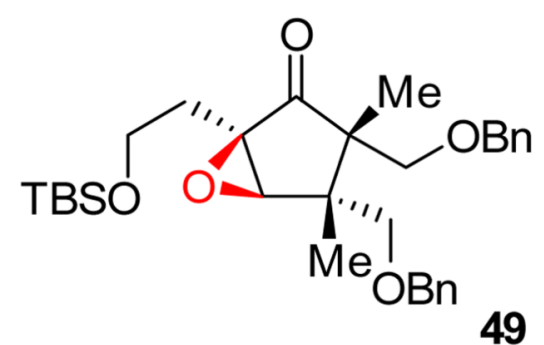

- this work

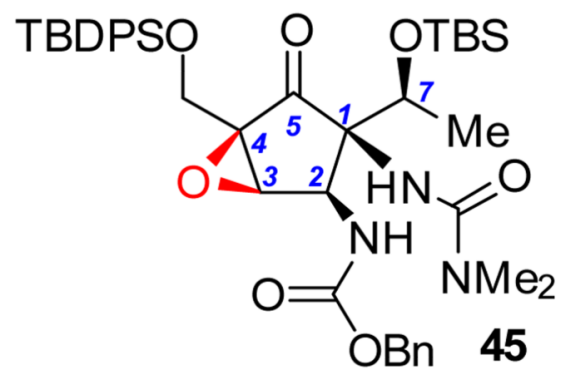
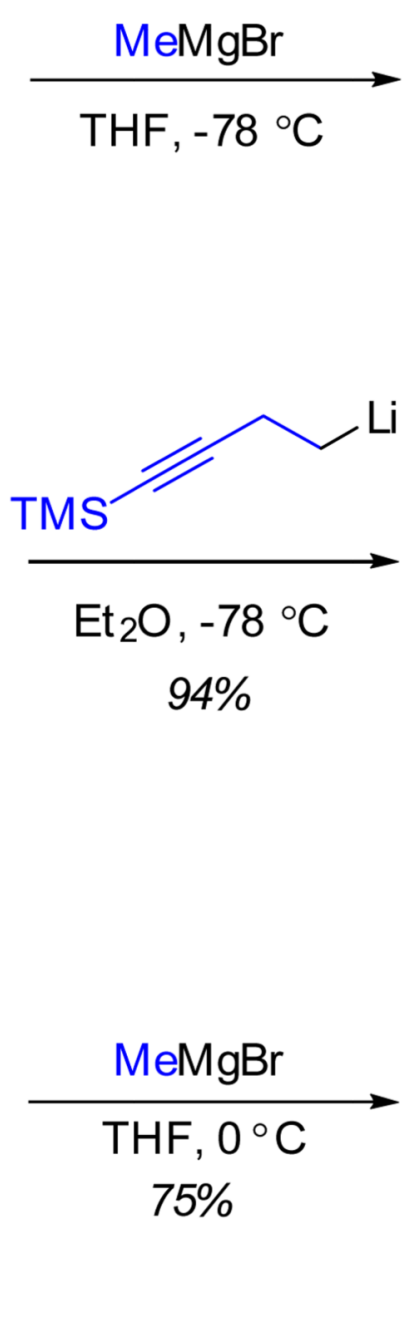

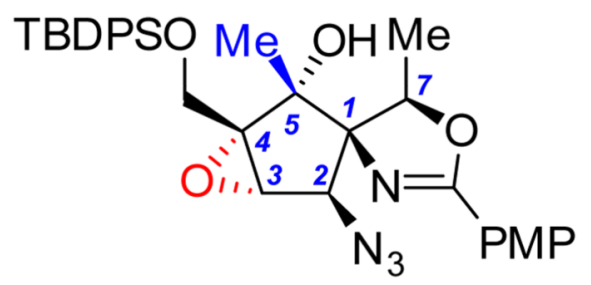

convex surface addition

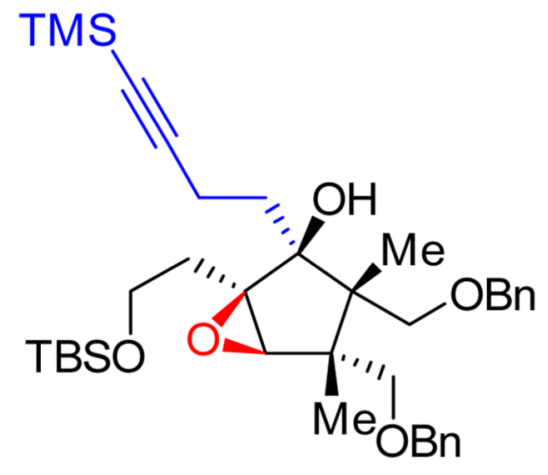

convex surface addition

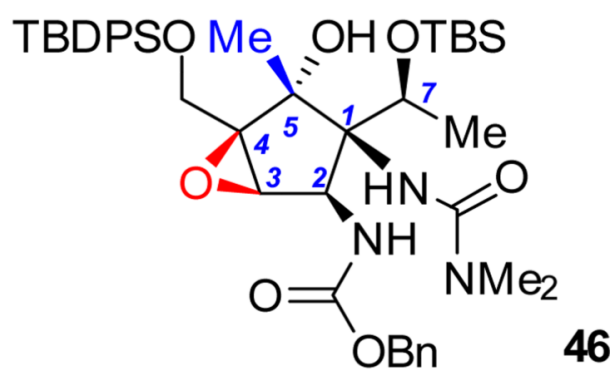

concave surface addition

Scheme 9.

Convex versus concave surface addition of carbon nucleophiles to oxobicyclo[3.1.0]hexanones 
A) Deuterium labeling studies of conversion of $\mathbf{4 2}$ to $\mathbf{4 3}$
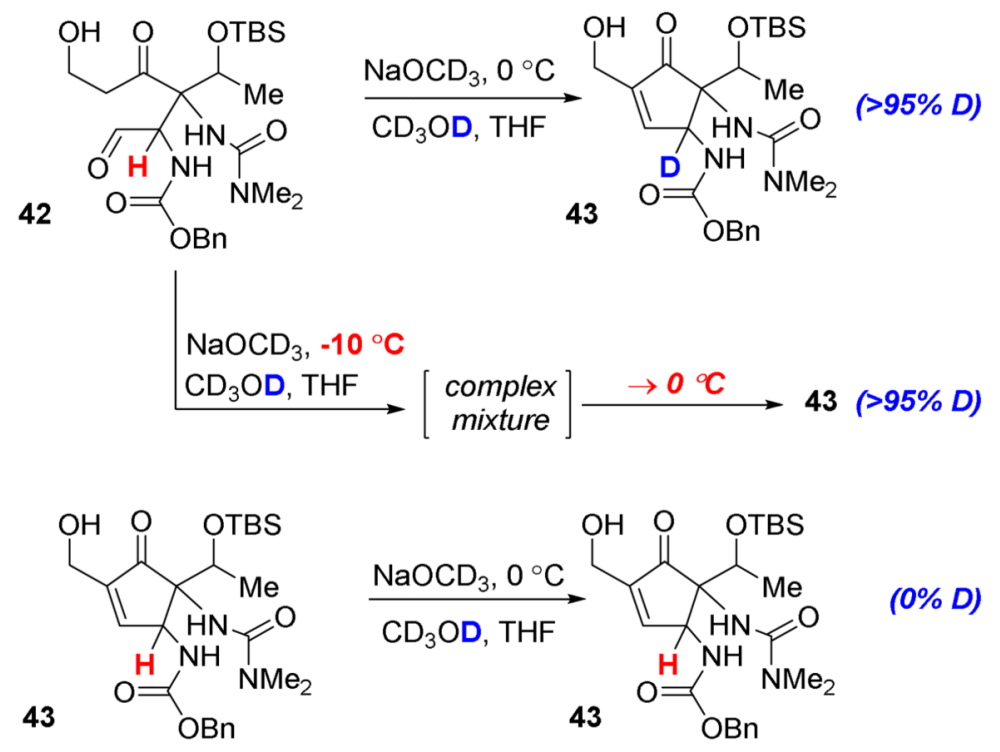

B) Synthesis of crystalline derivative $\mathbf{5 1}$

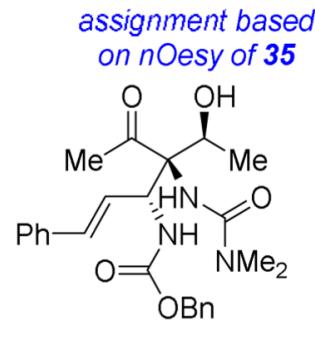

$(+)-34$

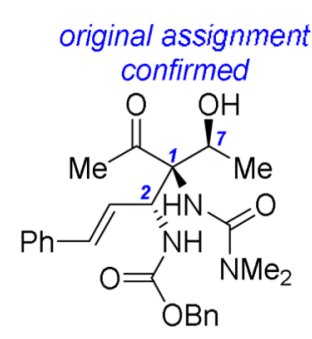

$(+)-34$

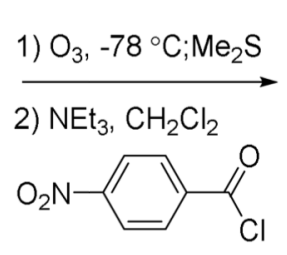

$\mathrm{Cl}$<smiles>CNC(=O)N[C@@]1(C)[C@H](NC(=O)OCc2ccccc2)[C@@H](OC(=O)[AlH2])OC1(C)C</smiles>

(x-ray) 51

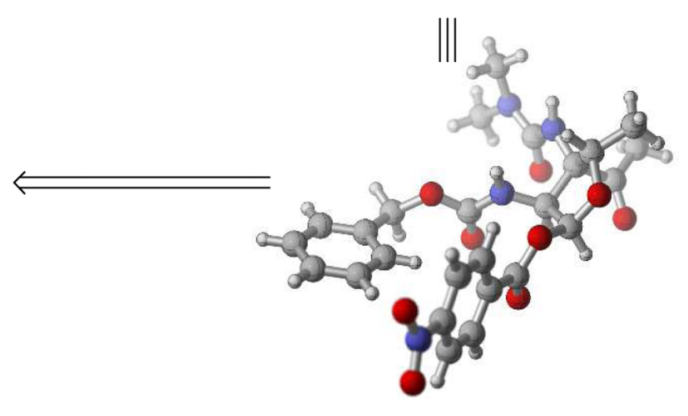

Scheme 10.

Deuterium-labeling experiments and unambiguous stereochemical assignment of 34 
<smiles>CC(=O)NC(C(C)=O)(C(C)=O)C(C=Cc1ccccc1)(NC(=O)OCc1ccccc1)C(=O)OCc1ccccc1</smiles>

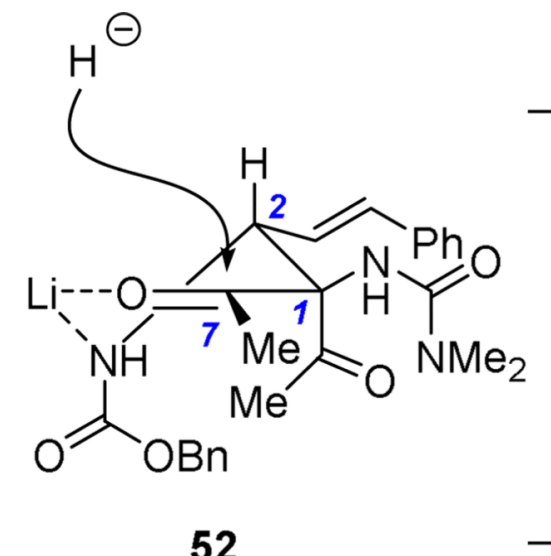

Scheme 11.

Proposed stereochemical model for LTBA reduction of 33 


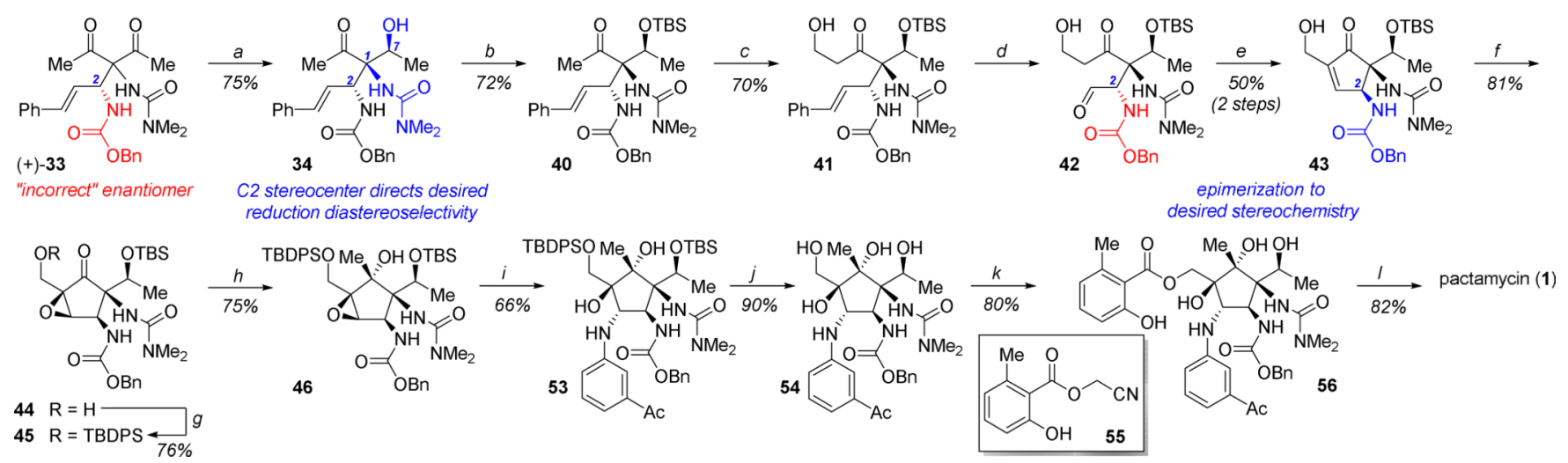

Scheme 12.

Completion of the synthesis of pactamycina

${ }^{a}$ Conditions: (a) LTBA, THF, $-35^{\circ} \mathrm{C}$; (b) TBSOTf, 2,6-lutidine, $\mathrm{CH}_{2} \mathrm{Cl}_{2},-78{ }^{\circ} \mathrm{C}$; (c) LDA,

THF, $-78{ }^{\circ} \mathrm{C}$, then $\mathrm{CH}_{2} \mathrm{O}(\mathrm{g}),-45^{\circ} \mathrm{C}$; (d) $\mathrm{O}_{3},-78{ }^{\circ} \mathrm{C}, \mathrm{CH}_{2} \mathrm{Cl}_{2}$; $\mathrm{Me}_{2} \mathrm{~S}$, rt; (e) $\mathrm{NaOMe}$,

THF:MeOH (4:1), $0{ }^{\circ} \mathrm{C}$; (f) $\mathrm{H}_{2} \mathrm{O}_{2}$ (30\% aq.), $\mathrm{NaOH}$ (20\% aq.), $\mathrm{MeOH}: \mathrm{CH}_{2} \mathrm{Cl}_{2}$ (7:1), $0{ }^{\circ} \mathrm{C}$;

(g) TBDPSCl, $\mathrm{NEt}_{3}$, DMAP $(10 \mathrm{~mol} \%), \mathrm{CH}_{2} \mathrm{Cl}_{2}, 0{ }^{\circ} \mathrm{C}$ to rt; (h) MeMgBr, THF, $0{ }^{\circ} \mathrm{C}$; (i) $\mathrm{m}$ acetylaniline, $\mathrm{Sc}(\mathrm{OTf})_{3}, \mathrm{C}_{7} \mathrm{H}_{8}, 60{ }^{\circ} \mathrm{C}$; (j) TBAF, THF, $0{ }^{\circ} \mathrm{C}$; (k) 55, $\mathrm{K}_{2} \mathrm{CO}_{3}$, DMA, rt; (l)

$\mathrm{H}_{2}, \mathrm{Pd}(\mathrm{OH})_{2} / \mathrm{C}$ (50\% mass), $\mathrm{MeOH}, \mathrm{rt}$ 